UNIVERSIDADE DE SÃO PAULO

ESCOLA DE ENFERMAGEM

ESPEDITO LADIER DO NASCIMENTO

EFEITO ANTIOXIDANTE DO FITOMEDICAMENTO

Echinodorus macrophyllus NA NEFROTOXICIDADE DO QUIMIOTERÁPICO CICLOFOSFAMIDA

São Paulo

2013 


\section{EFEITO ANTIOXIDANTE DO FITOMEDICAMENTO Echinodorus macrophyllus NA NEFROTOXICIDADE DO QUIMIOTERÁPICO CICLOFOSFAMIDA}

Dissertação apresentada ao Programa de Pós-Graduação em Enfermagem na Saúde do Adulto da Universidade de São Paulo para obtenção do título de Mestre em Ciências.

Área de Concentração: Enfermagem na Saúde do Adulto

Linha de Pesquisa: Tecnologia na Saúde do Adulto

Orientadora: Prof. $^{a}$ Dr. $^{a}$ Maria de Fátima Fernandes Vattimo

São Paulo 
AUTORIZO A REPRODUÇÃO E DIVULGAÇÃO TOTAL OU PARCIAL DESTE TRABALHO, POR QUALQUER MEIO CONVENCIONAL OU ELETRÔNICO, PARA FINS DE ESTUDO E PESQUISA, DESDE QUE CITADA A FONTE.

Assinatura:

Data:

Nascimento, Espedito Ladier do

Efeito antioxidante do fitomedicamento Echinodorus macrophyllus na nefrotoxicidade do quimioterápico ciclofosfamida / Espedito Ladier do Nascimento -- São Paulo, 2013.

$67 \mathrm{p}$.

Dissertação (Mestrado) - Escola de Enfermagem da Universidade de São Paulo.

Orient.: Prof. ${ }^{a}$ Dr. ${ }^{a}$ Maria de Fátima Fernandes Vattimo

Área de concentração: Enfermagem na saúde do adulto

1. Insuficiência renal aguda 2. Fitoterapia 3. Plantas medicinais 4. Antioxidantes 5. Antineoplásicos 6. Enfermagem I. Título. 
Nome: Espedito Ladier do Nascimento

Título: Efeito antioxidante do fitomedicamento Echinodorus macrophyllus na nefrotoxicidade do quimioterápico ciclofosfamida

Dissertação apresentada ao Programa de Pós-Graduação em Enfermagem na Saúde do Adulto da Escola de Enfermagem da Universidade de São Paulo para obtenção do Título de Mestre em Ciências.

Área de Concentração: Enfermagem na Saúde do Adulto

Aprovado em:

\section{Banca Examinadora}

Prof. Dr.

Instituição:

Julgamento:

Assinatura:

Prof. Dr.

Instituição:

Julgamento:

Assinatura:

Prof. Dr.

Instituição:

Julgamento:

Assinatura: 


\section{DEDICATÓRIA}

A minha mãe, por me motivar e incentivar sempre em minha trajetória, na vida.

Ao meu Pai (in memorian), pelos ensinamentos deixados, que muito contribuíram para minha formação.

Ao meu filho Vinicius, que é fonte de inspiração e motivação.

Aos meus irmãos, que mesmo com a distância, torcem e vibram com meu crescimento. 


\section{AGRADECIMENTTOS}

À Prof. ${ }^{a}$ Dr. ${ }^{a}$ Maria de Fátima Fernandes Vattimo, pela oportunidade e confiança, por compartilhar suas experiências e conhecimento.

À $\mathcal{D r} .{ }^{a}$ Mirian Watanabe, pela disponibilidade e atenção na realização deste trabalho.

À Cassiane Dezoti da Fonseca, pela colaboração durante a realização deste estudo.

Ao Dr. Rildo Volponi, pela realização da análise histológica.

Ao Prof. Dr. Marcelo José Pena Ferreira- Universidade Presbiteriana Mackenzie, pela realização da cromatografia deste trabalho.

À $\mathcal{N}$ eusa, pela companhia acolhedora e pelo incentivo de sempre.

Aos amigos Sheila, Magnólia, Fábio e Franciele, sempre prontos para ajudar.

Aos colegas do Hospital Sírio Libanês, pelo apoio e compreensão.

A minha família, pelo incentivo. 
Nascimento EL. Efeito antioxidante do fitomedicamento Echinodorus macrophyllus na nefrotoxicidade do quimioterápico ciclofosfamida. [dissertação]. São Paulo: Escola de Enfermagem da Universidade de São Paulo; 2013.

\section{RESUMO}

Medicamentos fitoterápicos são aqueles cuja matéria-prima é exclusivamente originária de vegetais, descartando-se qualquer associação que inclua em sua composição outras substâncias ativas isoladas não vegetais. A lesão renal aguda (LRA) é caracterizada pelo rápido declínio da função renal, definida por um aumento absoluto da creatinina sérica de pelo menos $0,3 \mathrm{mg} / \mathrm{dl}$, elevação de $50 \%$ ( 1,5 vezes) do valor basal ou redução do fluxo urinário, documentado como oligúria ou menor que $0,5 \mathrm{ml} / \mathrm{kg}$ por hora por mais de seis horas. Este estudo investigou o efeito protetor do Echinodorus macrophyllus (Ema) na nefrotoxicidade induzida pela ciclofosfamida. Foram utilizados ratos da raça Wistar, machos, adultos, distribuídos nos grupos: Controle: animais que receberam solução de cloreto de sódio $0,9 \%$ por via intraperitoneal (i.p.), (1,5ml/kg, dose única), Ema: animais que receberam Echinodorus macrophyllus, (2g/kg 1 x ao dia, durante 5 dias, por gavagem), CCF: animais que receberam ciclofosfamida (150mg/kg dose única, i.p.), CCF + Ema: animais que receberam Echinodorus macrophyllus e ciclofosfamida no $5^{\circ}$ dia (i.p.). Foram avaliadas a função renal (FR) (clearance de creatinina); a lesão oxidativa (peróxidos urinários, substâncias reativas ao ácido tiobarbitúrico - TBARS e tióis no tecido renal) e feita análise histológica renal (lesão tubulointersticial). Os resultados confirmaram a lesão nefrotóxica de caráter oxidativo induzida pela ciclofosfamida. O Ema demonstrou efeito renoprotetor antioxidante, com melhora da $F R$, redução dos níveis de peroxidação lipídica e metabólitos oxidativos. A análise histológica indicou dano significativo ao tecido renal pela CCF, que foi reduzido nos animais tratados com Ema. Este estudo demonstra claramente a LRA induzida pela ciclofosfamida e o efeito renoprotetor do Ema.

Palavras chave: Lesão renal aguda, Antioxidante, Ciclofosfamida, Alismataceae. 
Nascimento EL. Antioxidant effect of the phytomedicine Echinodorus macrophyllus in the nephrotoxicity of the cyclophosphamide. [Dissertation]. Sao Paulo: School of Nursing, University of São Paulo, 2013.

\begin{abstract}
Herbal medicines are those whose raw materials are exclusively originated from vegetables, excepting any association that includes in its composition other isolated active substances. Acute kidney injury (AKI) is characterized by a rapid decline in renal function defined by an absolute increase in serum creatinine of at least $0.3 \mathrm{mg} / \mathrm{dL}$, a $50 \%$ (1.5 times) baseline increase or urinary flow reduction, documented as oliguria or less than $0.5 \mathrm{ml} / \mathrm{kg}$ per hour for a period surpassing six hours. This study investigated the protective effect of Echinodorus macrophyllus (Ema) in cyclophosphamide-induced nephrotoxicity. We used male adults Wistar mice, divided into four groups: Control group: animals receiving sodium chloride solution 0.9 intraperitoneally (ip) $(1.5 \mathrm{ml} / \mathrm{kg}$, single dose); Ema: animals that received Echinodorus macrophyllus ( $2 \mathrm{~g} / \mathrm{kg}$ one time daily for 5 days by gavage); CCF: animals receiving cyclophosphamide (150mg/kg single dose, i.p), CCF + Ema: animals receiving Echonodorus macrophyllus and cyclophosphamide on day 5. We evaluated renal function (RF) (creatinine clearance), oxidative damage (urinary peroxides, thiobarbituric acid reactive substances - TBARS and thiols in kidney tissues) and we also carried out histologic kidney analyses (tubulointerstitial injury). Data confirmed the oxidative nephrotoxic injury induced by cyclophosphamide. Ema proved to have renoprotective and antioxidant effects, with improvement in RF, reduced levels of lipid peroxidation and oxidative metabolites. The histologic analysis indicated significant damage to renal tissue by CCF, which was reduced in animals treated with Ema. This study clearly demonstrates LRA induced by cyclophosphamide and the renoprotective effect of Ema.
\end{abstract}

Keywords: Acute kidney injury, Antioxidant, Cyclophosphamide, Alismataceae. 


\section{LISTA DE FIGURAS}

Figura 1 - Echinodorus macrophyllus ..................................... 21

Figura 2 - Protocolo experimental ................................................ 36

Figura 3 - Gaiola Metabólica ....................................................... 36

Figura 4 - Fotos de cortes histológicos.................................... 50 


\section{LISTAS DE TABELAS}

Tabela 1 - Resultados do peso corporal e função renal dos grupos Salina, Echinodorus macrophyllus (Ema), Ciclofosfamida (CCF) e Ciclofosfamida + Echinodorus macrophyllus (CCF+ Ema) - São Paulo - 2013 45

Tabela 2 - Resultados de peróxidos urinários dos grupos Salina, Echinodorus macrophyllus (Ema), Ciclofosfamida (CCF) e Ciclofosfamida + Echinodorus macrophyllus (CCF+ Ema) São Paulo - 2013 46

Tabela 3 - Resultados da dosagem de substâncias reativas ao ácido tiobarbitúrico dos grupos Salina, Echinodorus macrophyllus (Ema), Ciclofosfamida (CCF) + Ciclofosfamida e Echinodorus macrophyllus (CCF+Ema) - São Paulo - 2013 47

Tabela 4 - Resultados de tióis no tecido renal dos grupos Echinodorus macrophyllus (Ema), Ciclofosfamida (CCF) e Ciclofosfamida + Echinodorus macrophyllus (CCF+Ema) - São

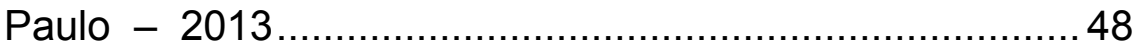

Tabela 5 - Resultados das alterações tubulointersticiais no tecido renal dos grupos Echinodorus macrophyllus (Ema), Ciclofosfamida (CCF) e Ciclofosfamida + Echinodorus macrophyllus (CCF+ Ema), São Paulo - 2013 49 


\section{LISTA DE ABREVIATURA}

\begin{tabular}{ll} 
AINEs & anti-inflamatórios não-esteroides \\
ALDH & enzima aldeído desidrogenase \\
ALDH1 & enzimas aldeído desidrogenase 1 \\
ALDH3A1 & enzimas aldeído desidrogenase 3A1 \\
ATP & adenosina trifosfato \\
BHT & 2[6]-di-tert-butil-p-cresol \\
CCF & ciclofosfamida \\
CEUA & Comissão de Ética no Uso de Animais \\
Clcr & clearance de creatinina \\
CrS & creatinina sérica \\
CrU & creatinina urinária \\
CYP & citocromo \\
DNA & ácido desoxirribonucleico \\
DTPA & dietilnotriamina - N,N,N',N' - penta-acetato \\
DTNB & 5,5'-ditio-bis (2-ácido nitrobenzoico) \\
DRC & doença renal crônica \\
EROs & espécies reativas de oxigênio \\
Fapesp & Fundação de Amparo à Pesquisa do Estado de São Paulo \\
FG & filtração glomerular \\
FK & tacrolimus \\
Fox-2 & método xilenol laranja versão-2 \\
FR & função renal \\
FU & fluxo urinário \\
GSH & glutationa \\
GSSG & glutationa oxidada \\
\hline
\end{tabular}




\begin{tabular}{|c|c|}
\hline GTS & glutationa-S-transferase \\
\hline ICAM & moléculas de adesão intracelular \\
\hline IL - 1 & interleucina - 1 \\
\hline IL - 2 & interleucina - 2 \\
\hline IL - 8 & interleucina - 8 \\
\hline i.p. & intraperitoneal \\
\hline $\mathrm{HO}-1$ & hemeoxigenase 1 \\
\hline LRA & lesão renal aguda \\
\hline LEMA & Laboratório Experimental de Modelos Animais \\
\hline MDA & malondealdeído \\
\hline MS & Ministério da Saúde \\
\hline $\mathrm{NaCl}$ & cloreto de sódio \\
\hline $\mathrm{NaOH}$ & hidróxido de sódio \\
\hline NO & óxido nítrico \\
\hline NTA & necrose tubular aguda \\
\hline OMS & Organização Mundial da Saúde \\
\hline PU & peróxido urinário \\
\hline RFG & ritmo de filtração glomerular \\
\hline SBCAL & Sociedade Brasileira de Ciência de animais de Laboratório \\
\hline SOD & superoxido dismutase \\
\hline SUS & Sistema Único de Saúde \\
\hline TBARS & substâncias reativas ao ácido tiobarbitúrico \\
\hline TNF-y & fator de necrose tumoral \\
\hline UTI & unidade de terapia intensiva \\
\hline v.o. & via oral \\
\hline $4-\mathrm{OH}-\mathrm{CCF}$ & 4-hidroxiciclofosfamida \\
\hline
\end{tabular}




\section{LISTA DE SÍMBOLOS}

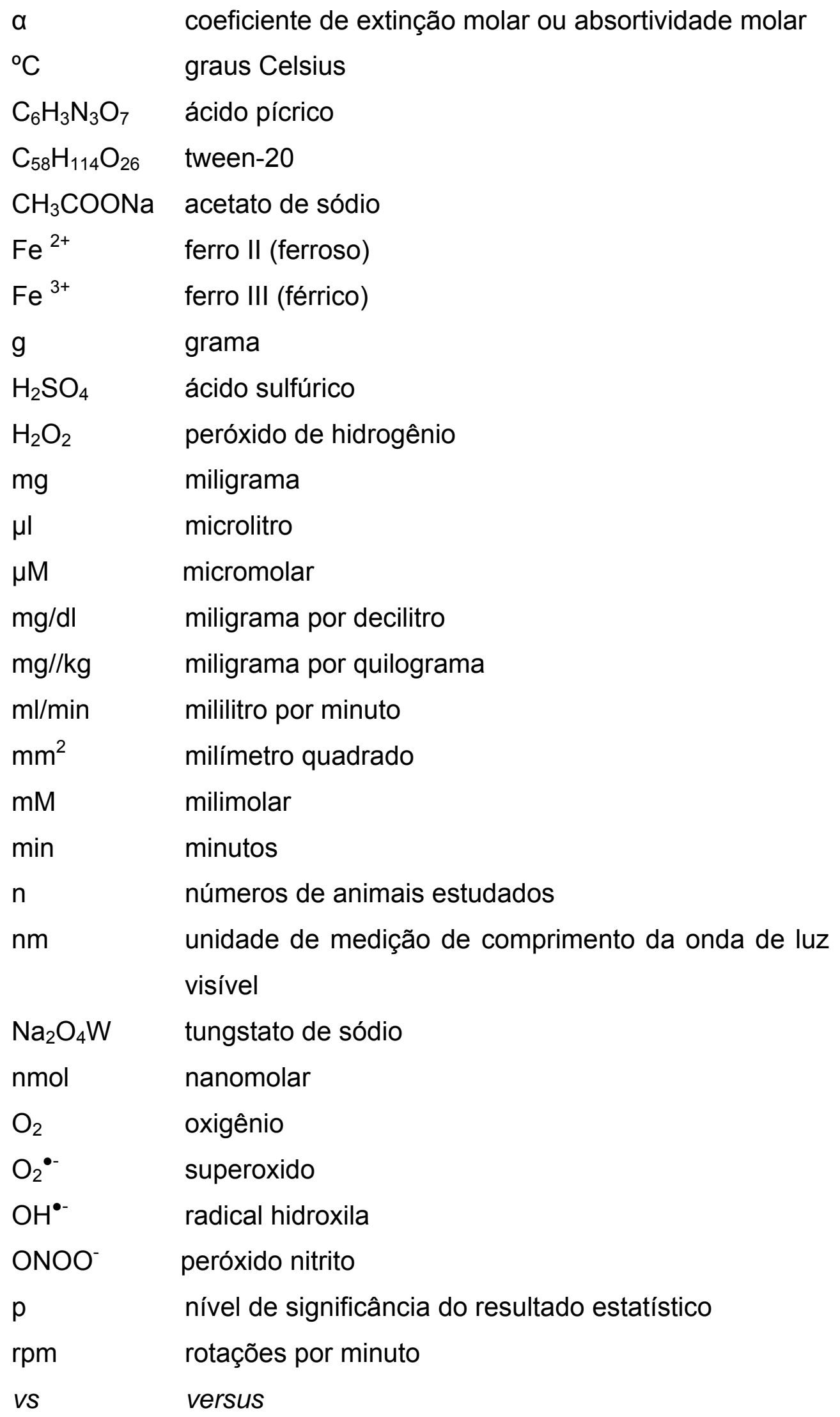




\section{SUMÁRIO}

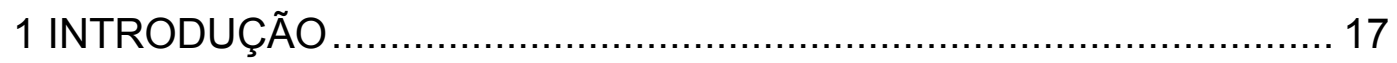

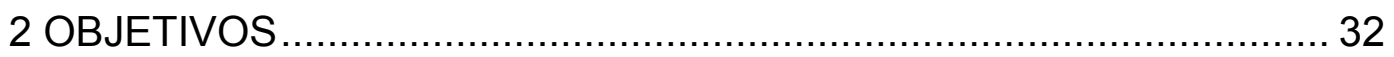

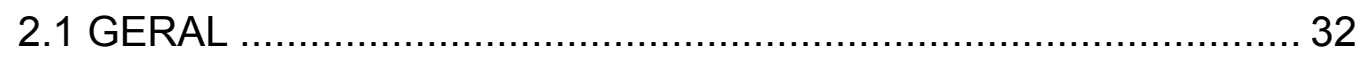

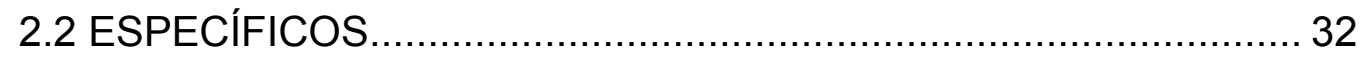

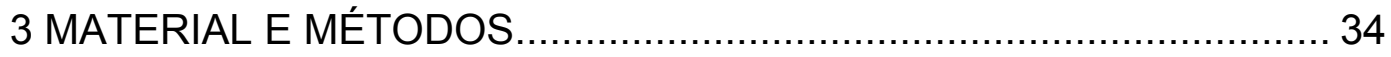

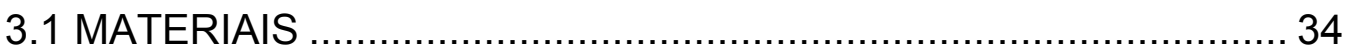

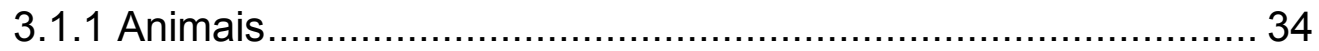

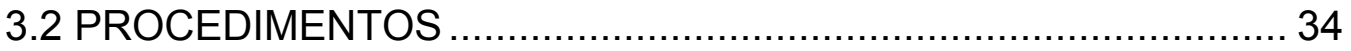

3.2.1 Administração da ciclofosfamida .............................................. 34

3.2.2 Administração do Echinodorus macrophyllus .......................... 35

3.2.3 Apresentação dos grupos experimentais ............................... 35

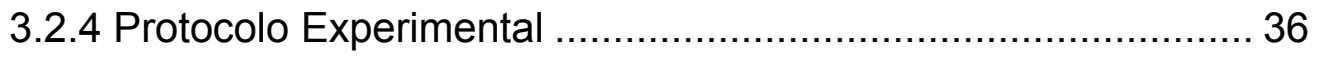

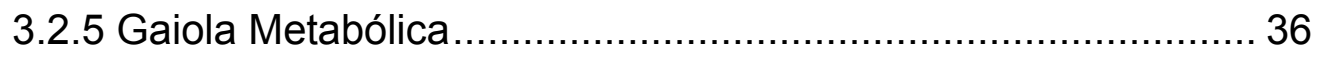

3.2.6 Coleta de amostras e preparo do tecido renal........................ 37

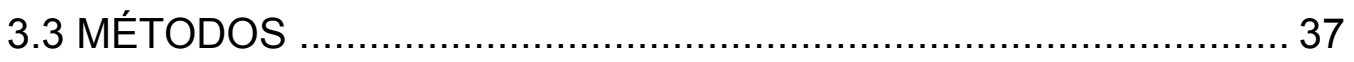

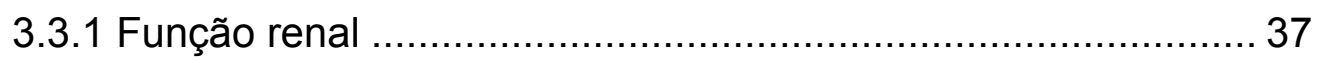

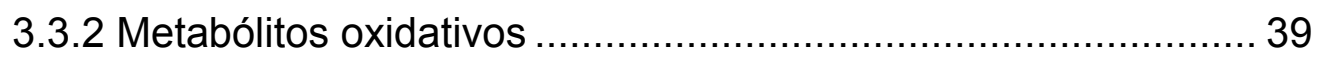

3.4 ANÁLISE HISTOLÓGICA DO TECIDO RENAL ........................... 42

3.4.1 Área de lesão túbulointersticial: escala Shih ........................... 42

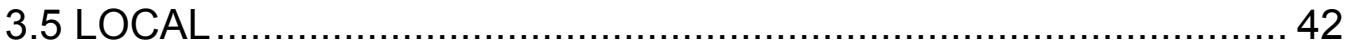

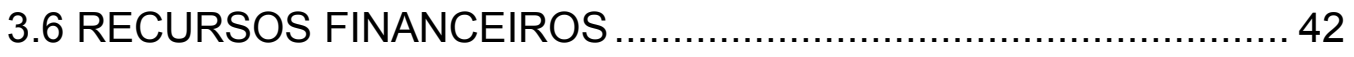

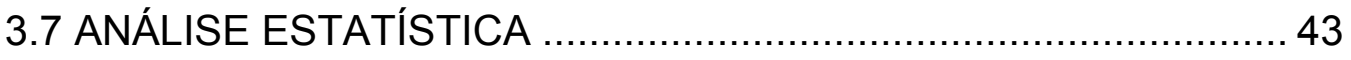

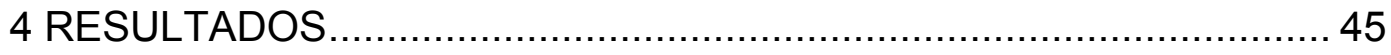

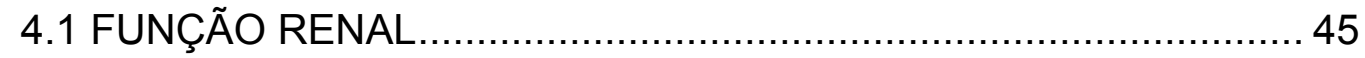


4.1.1 Clearance de creatinina............................................. 45

4.2 METABÓLITOS OXIDATIVOS .............................................. 46

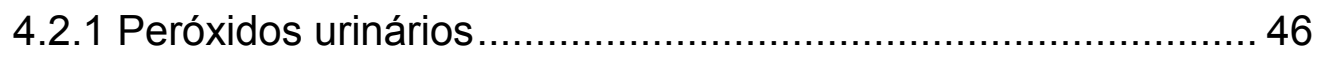

4.2.2 Dosagem de TBARS (substâncias reativas ao ácido tiobarbitúrico) na urina........................................................... 47

4.2.3 Tióis solúveis não proteicos no tecido renal ...................... 48

4.3 ANÁLISE HISTOLÓGICA DO TECIDO RENAL ..........................49 49

4.3.1 Área de lesão túbulointersticial: escala Shih ....................... 49

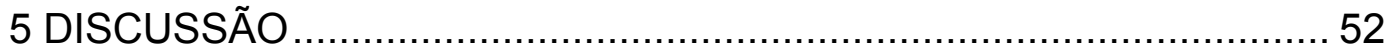

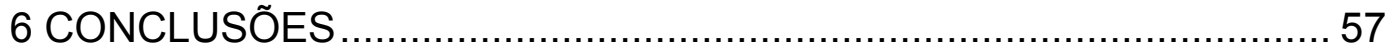

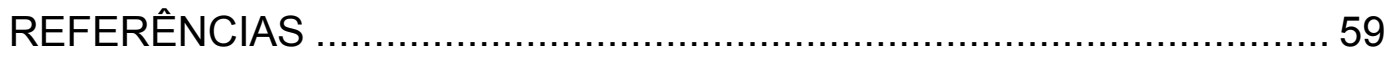

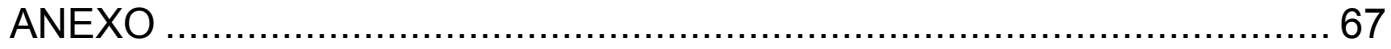


1 INTRODUÇÃO 


\section{INTRODUÇÃO}

A fitoterapia, que consiste em terapêutica caracterizada pelo uso de plantas medicinais em suas diferentes formas farmacêuticas, tem se tornado cada vez mais popular. São considerados medicamentos fitoterápicos aqueles cuja matéria-prima é exclusivamente originária de vegetais, descartando-se qualquer associação que inclua em sua composição outras substâncias ativas isoladas não vegetais. Os fitoterápicos que apresentam eficácia e segurança comprovada por estudos clínicos podem ser chamados de fitomedicamentos ${ }^{(1,2)}$. Neste estudo a terminologia empregada para se referir ao Echinodorus macrophyllus (Ema) será fitomedicamento.

A utilização de plantas medicinais é notória nos últimos anos, devida aos seus efeitos potencialmente benéficos à saúde humana. No entanto, existe uma carência de informação sobre seus efeitos mutagênicos na maioria dos princípios ativos. Muitos fitomedicamentos podem ser eficazes, mas necessitam de investigação no sentido de detectar efeitos secundários tóxicos. Isto é particularmente importante, porque muitas plantas sintetizam substâncias tóxicas para a defesa contra vírus, bactérias e fungos, e estes compostos podem ter efeitos potencialmente deletérios em seres humanos ${ }^{(3)}$.

Atualmente, a ciência busca unificar a evolução tecnológica e desenvolver estudos mais consistentes com o que a natureza oferece, considerando o respeito à cultura dos povos sobre o uso de produtos ou ervas medicinais para cura. No passado, o principal meio terapêutico conhecido para tratamento de males da população eram as plantas medicinais. A partir do conhecimento de plantas e seu uso, foram descobertos alguns medicamentos utilizados na medicina tradicional. Entre eles destacam-se os salicilatos e digitálicos ${ }^{(4)}$. 
Existe na América Latina, em especial nas regiões tropicais, uma diversidade de espécies de plantas medicinais de uso local. Essa abundância gera uma relação custo-benefício bem menor para a população, além de promover saúde a partir de plantas produzidas localmente. No Brasil existem diversidades e peculiaridades, com concepções, opiniões, valores, conhecimentos, práticas e técnicas diferentes, que precisam ser incorporadas e respeitadas no cotidiano, influenciadas por hábitos, tradições e costumes ${ }^{(4)}$, porém estudos que comprovem segurança e eficácia são raros.

As características desejáveis de plantas medicinais são a eficácia, baixo risco, assim como reprodutibilidade e constância de sua qualidade. Nesse sentido, o trabalho multidisciplinar é de fundamental importância na formulação dos fitoterápicos, pois promove uma seleção correta de espécie vegetal, cultivo adequado e realização de avaliações de teores dos princípios ativos visando à manipulação e à aplicação desses fitomedicamentos na prática clínica ${ }^{(4)}$.

Os princípios ativos de uma planta podem ser aproveitados respeitando um rigoroso preparo, ou seja, cada parte a ser usada, princípio ativo a ser extraído ou doença a ser tratada, requer uma forma de manuseio e uso. Os efeitos colaterais conhecidos para plantas medicinais são devidos ao preparo inadequado, tais como falha na identificação da planta, na padronização, no processamento, contaminação e adulteração das plantas ${ }^{(4)}$.

Nesse sentido, a utilização de ervas medicinais em formulações deve seguir rigoroso critério e orientação de profissionais especializados da área de saúde, pois elas podem apresentar efeitos farmacológicos similares, potencializando suas ações ${ }^{(5)}$. A associação de fitoterápicos e medicamentos alopáticos é possível, desde que haja supervisão e acompanhamento por profissionais, levando em consideração a possibilidade de sinergismo ${ }^{(4)}$. 
A carência de informações técnicas para a maioria das plantas medicinais compromete a qualidade, eficácia e segurança no seu uso. A eficácia e a segurança dependem de um cultivo doméstico adequado, controle rigoroso na produção, incentivos a estudos biotecnológicos para o melhoramento genético, uniformidade e material de qualidade ${ }^{(4)}$.

No Brasil, a fitoterapia é institucionalizada mediante recomendação interministerial e resolução do Ministério da Saúde (MS) condicionando o uso de plantas medicinais no Sistema Único de Saúde (SUS) a estudos de caracterização de princípios ativos e de mecanismos de ação, dentre outras investigações científicas ${ }^{(5)}$.

Atualmente, verifica-se um crescimento na comercialização de fitomedicamentos no mercado farmacêutico brasileiro ${ }^{(6)}$. No entanto, observa-se nestes fármacos a predominância de extratos de plantas provenientes de outros países, ou seja, daquelas que não se desenvolvem espontaneamente no Brasil ${ }^{(7)}$. Uma explicação para que este fato ocorra é a existência no exterior de mais informações científicas, facilitando o seu registro junto aos órgãos competentes nacionais.

A carência de pesquisas científicas para plantas nativas brasileiras agrava este quadro e acarreta algumas dificuldades para o seu aproveitamento como matéria-prima pela indústria de fitomedicamentos. Nesse contexto, podemos citar a espécie nativa brasileira, Ema, da família Alismataceae, conhecida vulgarmente por chapéu-de-couro, chámineiro, erva-de-pântano, erva-de-bugre, congonha-do-campo e erva-dobrejo, amplamente utilizada na medicina popular nas regiões sudeste e centro oeste, mas que ainda necessita de informações científicas mais consistentes para o seu aproveitamento no desenvolvimento de fitomedicamentos $^{(8)}$.

A família Alismataceae é constituída por espécies arbóreas adaptadas a locais úmidos e semissombreados, representada por aproximadamente 14 gêneros e 60 espécies. Os gêneros mais abundantes são Echinodorus (25), Sagittaria (20) e Alisma (5) ${ }^{(8)}$. 
No Brasil ocorrem espontaneamente dois gêneros da família Alismataceae. A espécie macrophyllus pode ser encontrada nos estados de Minas Gerais e São Paulo, preferencialmente em regiões alagadas. Suas folhas são utilizadas popularmente para o tratamento de várias enfermidades, como reumatismo e sífilis, e é conhecida por sua ação diurética: auxilia na diminuição de ácido úrico e possui propriedade antiinflamatória e antioxidante. Estudo realizado sobre a composição química da espécie revelou presença de flavonoides com efeito antioxidante ${ }^{(8)}$.

Os flavonoides são compostos polifenólicos biossintetizados a partir da via dos fenilpropanoides e do acetato, precursores de vários grupos de substâncias como aminoácidos alifáticos, terpenoides, ácidos graxos, dentre outros. Eles participam de importantes funções no crescimento, desenvolvimento e na defesa dos vegetais contra o ataque de patógenos. Estão presentes na maioria das plantas, concentrados em sementes, frutos, cascas, raízes, folhas e flores. As principais fontes de flavonoides incluem frutos (uvas, cerejas, maçã, groselhas, frutas cítricas, entre outros) e hortaliças (pimenta, tomate, espinafre, cebola, brócolis, dentre outras folhosas), sendo seu consumo estimado na dieta humana entre $1-2 \mathrm{~g} / \mathrm{dia}^{(9)}$.

A toxidade in vitro e in vivo do extrato aquoso das folhas da Ema foi analisada em experimentos realizados com ratos, mostrando a ausência de efeito genotóxico ${ }^{(10)}$.

A Ema apresenta folha peciolada, oval, de base cordiforme e aguda ou acuminada no ápice, limbo inteiro, de cor verde-escura, comprimento de 20 a $40 \mathrm{~cm}$, largura de 15 a $35 \mathrm{~cm}$ na região próxima à base, de superfície rugosa, áspera, pedalinérvea, com 11 a 13 nervuras principais, salientes na parte inferior. Seu pecíolo é longo, com coriáceo medindo até $70 \mathrm{~cm}$ de comprimento, sulcado e provido de estrias longitudinais. Suas flores são brancas, hermafroditas, perfeitas, numerosas, dispostas em racimos alongados ${ }^{(8)}$. 


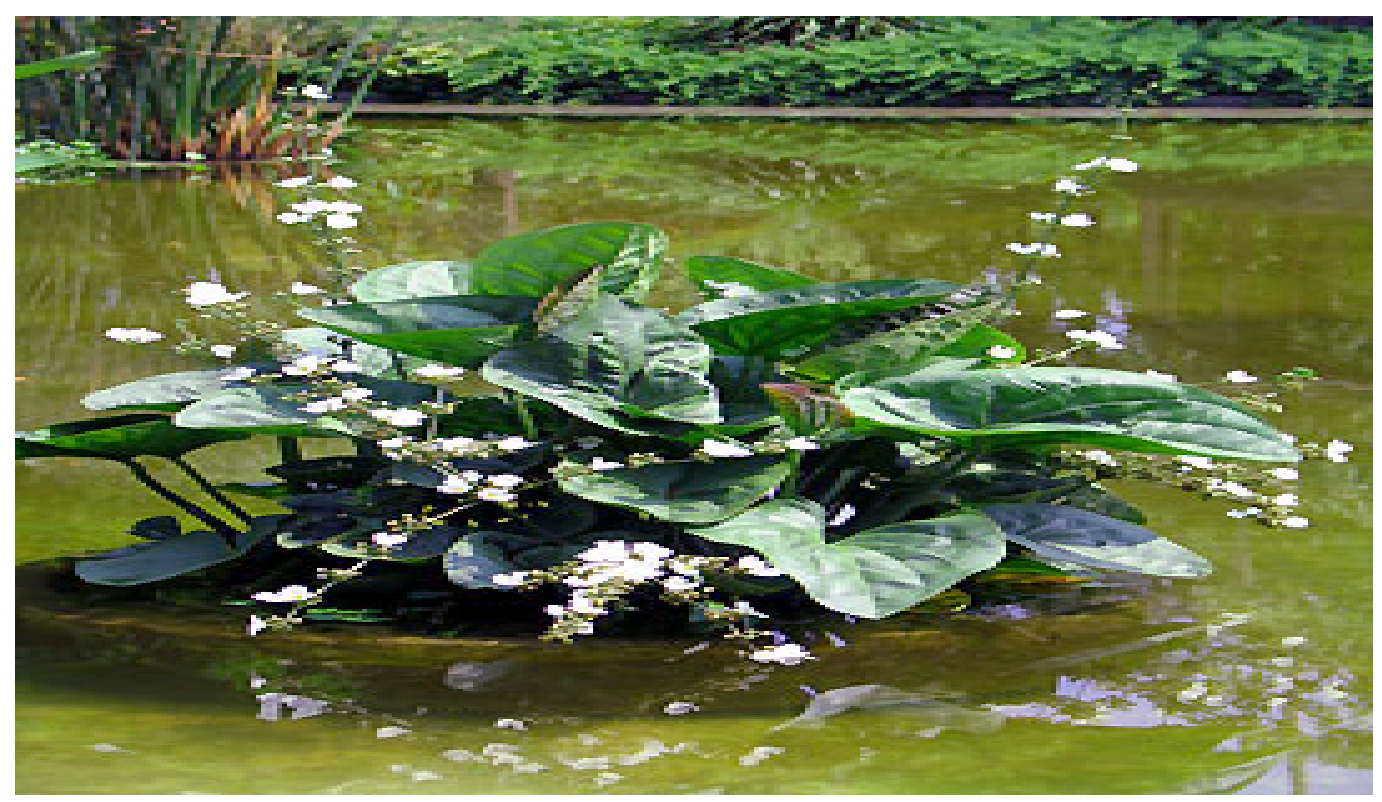

Figura 1 - Echinodorus macrophyllus - Jardim Tropical

Vários estudos descrevem 0 uso de fitomedicamentos concomitante com quimioterápicos, pela ação anti-inflamatória que pode reduzir a nefrotoxicidade. O fitomedicamento Curcumin mostrou redução da nefrotoxicidade induzida pela cisplatina. O efeito antioxidante da quercetin foi demonstrado em estudo sobre rabdomiólise, evidenciando seu potencial efeito renoprotetor e a Ipomoea obscura (L.) demonstrou ação renoprotetora e anti-inflamatória em modelo animal realizado com a ciclofosfamida $^{(11,12,13)}$.

A repercussão clínica e o impacto na saúde pública da lesão renal aguda (LRA) têm se mostrado resistentes a estratégias tradicionais de tratamento. A abordagem preventiva dessa síndrome poderá resultar em evoluções clínicas mais favoráveis. A utilização de fitomedicamentos nesse cenário, à semelhança do que já ocorreu em doenças cardiovasculares com o uso do vinho pelas propriedades antioxidantes derivadas dos flavonoides ${ }^{(14)}$, pode trazer benefícios relevantes para o seu controle em diversas apresentações ${ }^{(15)}$.

A LRA é uma síndrome que já levou mais de 25 nomes e 35 definições. Após consenso internacional, tal lesão foi caracterizada pelo rápido declínio da função renal, definida por um aumento absoluto da 
creatinina sérica de pelo menos $0,3 \mathrm{mg} / \mathrm{dl}$, elevação de $50 \%$ (1,5 vezes) do valor basal ou redução do fluxo urinário, documentado como oligúria ou menor que $0,5 \mathrm{ml} / \mathrm{kg}$ por hora por mais de seis horas ${ }^{(16)}$.

A LRA é uma complicação em cerca de $5 \%$ das hospitalizações e até $30 \%$ das internações em unidade de terapia intensiva (UTI). A necrose tubular aguda (NTA) é responsável por mais de 50\% de LRA em pacientes hospitalizados e mais de $76 \%$ dos casos em pacientes de UTI, sendo a sepse a condição mais comumente associada ${ }^{(17,18,19)}$. A prevalência de LRA varia de acordo com os valores de creatinina utilizados no diagnóstico em cada estudo e tem importante impacto na mortalidade ${ }^{(20)}$.

A incidência de LRA aumenta com a idade, sendo 3,5 vezes maior nos pacientes acima de 70 anos $^{(17)}$, justificada pela redução progressiva do ritmo de filtração glomerular (RFG) com a idade, $\left(1 \mathrm{ml} / \mathrm{min} / 1,73 \mathrm{~m}^{2}\right.$ por ano após os 30 anos), associada à maior prevalência de comorbidades como Diabetes mellitus, hipertensão arterial e hiperlipidemia. Pacientes com insuficiência renal crônica (IRC) tem maior chance de evoluir com rim terminal após episódio de agudização da insuficiência renal ${ }^{(21)}$.

A nefrotoxicidade e a isquemia são as causas mais comuns de LRA em ambiente hospitalar. A LRA é caracterizada pelo aumento plasmático de produtos do metabolismo protéico (creatinina e ureia), redução do RFG (clearance de creatinina) ou redução do fluxo urinário e está relacionada ao aumento no tempo de hospitalização ${ }^{(22,23)}$. Está diretamente relacionada às funções essenciais do órgão, sendo as mais importantes o metabolismo e a excreção de agentes terapêuticos e sua ação como eliminador primário de fármacos e toxinas. Outras funções importantes são a depuração de resíduos de produtos endógenos e controle da volemia ${ }^{(24)}$.

A alta concentração de toxinas, que predispõe o rim à nefrotoxicidade, é consequência do alto fluxo sanguíneo renal, que corresponde a $25 \%$ do débito cardíaco. As células do segmento S3 do 
túbulo proximal e alça de Henle, localizada na porção externa da medula, estão em ambiente relativamente hipóxico e altas taxas metabólicas são necessárias para o transporte ativo de solutos por vias de Na-K-ATPase, o que aumenta a sensibilidade à lesão por substâncias potencialmente nefrotóxicas $^{(25,26)}$.

Vários agentes terapêuticos têm potencial nefrotóxico. Exemplos recorrentes incluem antimicrobianos, quimioterápicos, analgésicos e imunossupressores $^{(21)}$. A alta concentração de substâncias tóxicas e seus metabólitos no tecido renal também resultam em LRA por toxicidade tubular direta, desequilíbrio de agentes vasoativos (redução de prostaglandinas, aumento da tromboxano), lesão isquêmica e intensa resposta inflamatória ${ }^{(27,28)}$.

O curso clínico da LRA é didaticamente dividido em três fases. A fase inicial, que correspondente à exposição do órgão ao agente nefrotóxico ou período de isquemia; a fase de manutenção, com instalação da lesão renal, caracterizada em muitas circunstâncias por diminuição do débito urinário, tendo duração de aproximadamente uma a três semanas e a fase de recuperação, associada ao processo de regeneração tubular e reparo parcial ou total da lesão inicial ${ }^{(29,30)}$. A determinação da duração de cada fase depende da preexistência de doença renal, duração e natureza, gravidade e tempo de insulto.

O progresso no tratamento clínico da LRA tem sido frustrante. Vários agentes (por exemplo, fatores de crescimento, antiapoptóticos etc.) terapêuticos na LRA não reproduziram no ambiente clínico os bons resultados obtidos em modelos experimentais ${ }^{(31)}$. Em parte, a dificuldade de se identificarem as fases anteriormente descritas justifica esse cenário $^{(32)}$.

A fisiopatologia da LRA é composta por vários mecanismos como a vasoconstrição da microvasculatura renal, envolvendo espécies reativas de oxigênio (EROs), resposta inflamatória e ativação de mecanismos de proteção celular $^{(31,33,34)}$. 
A administração de altas doses de fármacos pode desencadear desequilíbrio hemodinâmico na microcirculação renal, com elevação dos níveis de cálcio intracelular, diminuição da produção de óxido nítrico (NO) derivado do endotélio, que corroboram para uma vasoconstrição medular, causando nefrose osmótica. Por outro lado, a hipoperfusão tubular se instala com alterações na polaridade das células, como deslocamento da bomba Na-K-ATPase da membrana basolateral para o domínio apical. O enfraquecimento no transporte de sódio e água fora do lúmen e túbulo proximal aumenta as atividades de feedback tubuloglomerular distal, prolongando a vasoconstrição intrarrenal ${ }^{(35)}$.

Os mecanismos de toxicidade direta ativam a cascata de resposta inflamatória via produção de leucócitos na microvasculatura renal. Concomitantemente, com a disfunção endotelial, são gerados inúmeros mediadores pró-inflamatórios, os quais representam uma resposta de adaptação ao desequilíbrio, com o desbalanço entre fatores vasoconstritores e vasodilatadores ${ }^{(36)}$. A lesão endotelial ou alteração da função endotelial são resultantes da vasoconstrição local, que favorece o edema celular, o aumento da expressão das moléculas de adesão e, consequentemente, a ativação leucócito-endotelial. A despolarização celular no citoesqueleto induz a expressão de inúmeras espécies vasoativas e manifesta uma reatividade vascular aberrante, com o aumento do tônus basal e prejuízo na autorregulaçao do fluxo sanguíneo renal, prevalecendo a ação de vasoconstritores como a endotelina ${ }^{(36,37,38)}$.

A resposta inflamatória e a vasoconstrição da microvasculatura resultam da geração de EROs caracterizando desequilíbrio redox ou peroxidação lipídica. As EROs representam a produção intracelular desbalanceada de alguns agentes intermediários nocivos à integridade de várias biomoléculas, incluindo proteínas, lipídios e DNA ${ }^{(34)}$.

As EROs podem lesar as células do epitélio tubular por via direta ou por meio da ativação de processos inflamatórios. A resposta inflamatória é mediada pelo aumento da expressão de inúmeras citocinas 
que incluem $o$ fator de necrose tumoral (TNF- $\alpha$ ), interferon- $\gamma$ e interleucinas (IL-1, IL-2, IL-8). Essa citocinas, juntamente com as EROs e os eicosanoides, ativam os leucócitos e aumentam a expressão de moléculas de adesão endotelial como as ICAM-1, selectina P e E. A ativação das células endoteliais e de leucócitos resulta em apoptose e necrose celular. Sendo assim, um mecanismo de retroalimentação dinâmica perdura mesmo após a interrupção do insulto inicial ${ }^{(37,38)}$.

As EROs comprometem a vitalidade celular, a ação de fatores de crescimento e proliferação celular, o reparo e regeneração tecidual, os processos inflamatórios e imunológicos e a regulação de vários sistemas como o hemodinâmico, homeostático e vascular ${ }^{(39)}$. Por outro lado, as EROs também têm um papel fisiológico e, quando produzidas de forma contínua em pequenas quantidades no metabolismo oxidativo microssomal, se caracterizam pelo radical superóxido $\left(\mathrm{O}_{2}{ }^{\bullet-}\right)$, o não radical peróxido de hidrogênio $\left(\mathrm{H}_{2} \mathrm{O}_{2}\right)$ e o radical hidroxila $\left(\mathrm{OH}^{\bullet-}\right)^{(36)}$. Apesar da conotação tóxica, os baixos níveis de EROs são necessários para manutenção de funções celulares que incluem a modulação de várias quinases e a ativação de fatores de transcrição envolvidos com a regulação gênica de algumas proteínas. O desequilíbrio entre esses agentes oxidantes e enzimas antioxidantes endógenas, em favor dos primeiros, é que representa o mecanismo redox ${ }^{(40)}$.

A homeostase celular é mantida devido à existência de mecanismos de defesa antioxidantes, que são determinados por várias enzimas antioxidantes endógenas, destacando-se a superoxido dismutase (SOD) para eliminação do radical $\mathrm{O}_{2}{ }^{\bullet-}$, a catalase e a glutationa peroxidase, que são relacionadas à eliminação de $\mathrm{H}_{2} \mathrm{O}_{2}$ e peróxidos orgânicos ${ }^{(37,40)}$. $\mathrm{O} \mathrm{H}_{2} \mathrm{O}_{2}$ tem alta habilidade de penetrar nas membranas biológicas, sendo um sinalizador intracelular de moléculas. Uma vez produzido em excesso, o $\mathrm{H}_{2} \mathrm{O}_{2}$ ativa o sistema enzimático antioxidante, a saber: catalase, glutationa peroxidase e a $\operatorname{SOD}^{(37)}$. 
A glutationa peroxidase é considerada uma enzima de alta efetividade entre as enzimas antioxidantes, pois atua contra os peróxidos lipídicos e $\circ \quad \mathrm{H}_{2} \mathrm{O}_{2}$, utilizando a $\mathrm{NADPH}$ (nicotinamida adenina dinucleotídeo de fosfato), como demonstrado anteriormente, como espécie redutora. É conhecida como o antioxidante endógeno de maior peso molecular do citoplasma, com presença significativa no rim $^{(41)}$.

Os mecanismos envolvidos na LRA estão presentes, tanto no modelo de isquemia quanto na toxicidade, com graduações diferentes, que na prática clínica acabam por definir padrões menos severos para as lesões por nefrotoxicidade em situações em que não estão presentes outros agravos. Há que se ressaltar que circunstâncias em que se constata LRA isolada de outras ocorrências mórbidas são raras ${ }^{(33)}$.

A complexidade das doenças graves exige o uso de múltiplos fármacos, os quais, associados ou não, apresentam risco de nefrotoxicidade.

No caso de doenças oncológicas, o tratamento pode ser realizado através de cirurgia, radioterapia e quimioterapia, dependendo a escolha das características de cada paciente, bem como de seu estado e características do tumor, como aspectos patológicos e morfológicos, sua localização e extensão ${ }^{(42)}$. Frequentemente o tratamento do câncer está associado a várias reações adversas, pois os medicamentos utilizados não têm ação específica e direta para as células tumorais, atingindo estruturas normais que se renovam constantemente, como medula óssea, pelos e a mucosa do tubo digestivo, além de causarem muitos efeitos tóxicos como mielossupressão (depressão da função da medula óssea), nefrotoxicidade, aplasia medular, náuseas e vômitos, entre outros ${ }^{(43,44)}$.

De um modo geral, as reações adversas estão relacionadas a todas as classes de agentes antineoplásicos. Desde 1940, os agentes alquilantes são usados no tratamento do câncer, pois esses agentes interagem com o DNA, inibindo o novo material e causando lesão ${ }^{(45)}$. 
Os agentes alquilantes foram os primeiros agentes antineoplásicos descobertos, usados na Segunda Guerra Mundial, especialmente originado das mostardas nitrogenadas. Esta descoberta ocorreu durante um ataque aéreo alemão que destruiu um depósito de gás mostarda americano na Itália. O gás induziu mielodepressão (incapacidade da medula óssea de repor os elementos sanguíneos circulantes) intensa nos indivíduos expostos ${ }^{(45,46)}$.

Em 1946, após pesquisas realizadas sobre os efeitos biológicos das mostardas nitrogenadas, descobriu-se que essas manifestações eram devidas à alquilação. Os tecidos com alta taxa de proliferação eram mais suscetíveis aos agentes alquilantes, especialmente nas leucemias e linfomas ${ }^{(42)}$. Estes medicamentos têm como principal alvo o ciclo celular, em que interrompem ou interferem em etapas importantes da proliferação celular e por consequência levam as células em duplicação à morte ${ }^{(47)}$.

A ciclofosfamida (CCF) é um agente alquilante da classe das oxazafosforinas, citostático, usado desde 1950. É efetivo no tratamento de doenças neoplásicas, como tumores sólidos e linfomas, e não neoplásicas, como a artrite reumatoide e o lúpus eritematoso sistêmico. Esse fármaco e seus metabólitos causam inflamação aguda na bexiga e podem causar lesão renal ${ }^{(48)}$.

A CCF pode ser administrada por via oral (v.o) ou via intravenosa, com dosagens variadas, sendo de fácil absorção por v.o. A dose, o tempo e a via de administração da CCF dependem do tipo de patologia. A dose usada no tratamento de doenças oncológicas apresenta variações, dependendo da terapêutica estabelecida ${ }^{(49)}$.

Clinicamente, a toxicidade da CCF varia, com sintomas urinários irritativos e transitórios e hematúria leve por cistite hemorrágica, sem risco para a vida. A urotoxicidade está relacionada à formação de metabólitos tóxicos da CCF no fígado e, em parte, à atividade de alquilação direta no trato urinário ${ }^{(50)}$. A principal ativação da CCF ocorre no fígado. A dose administrada é ativada pelo sistema microssomal enzimático citocromo 
P450 (CYP), para formação do metabólito ativo 4-hidroxiciclofosfamida (4$\mathrm{OH}-\mathrm{CCF}$ ), que existe em equilíbrio com seu tautômero, a aldofosfamida. Outras enzimas do CYP estão envolvidas na bioativação da CCF em humanos. O CYP2B6 contribui com aproximadamente $45 \%$ da $4-\mathrm{OH}-\mathrm{CCF}$, o CYP3A4 com aproximadamente $12 \%{ }^{(51)}$.

A 4-OH-CCF é altamente difundida para o interior da célula. Sua elevada instabilidade permite que seja espontaneamente decomposta em fosforamida mostarda, por ß-eliminação da acroleína, um aldeído altamente reativo que pode aumentar o dano celular induzido pela CCF, possivelmente por conjugação e depleção da glutationa celular ${ }^{(49)}$. $O$ mecanismo de toxicidade da acroleína se faz com a depleção dos antioxidantes, evento esse denominado peroxidação lipídica ${ }^{(52)}$. A acroleína é um aldeído $\alpha$ altamente eletrofílico, $\beta$-insaturado, para o qual os humanos são expostos em uma variedade de situações ambientais, especialmente como um componente do fumo. Além disso, é um metabolito da CCF. A acroleína é um fator importante para a toxicidade e, talvez, para a atividade terapêutica do agente anticancerígeno ${ }^{(53)}$.

A fosforamida mostarda é um agente alquilante do DNA e, portanto, considerada o metabólito responsável pelo efeito alquilante da CCF. Entretanto, a fosforamida mostarda circulante pode contribuir para a citotoxicidade, pois é altamente ionizada em pH fisiológico e, assim, impedida de penetrar na célula. Portanto, somente a fração da fosforamida mostarda formada no interior da célula pode ser considerada citotóxica. Já que a 4-OH-CCF se difunde completamente para o interior da célula, seguida por liberação espontânea da fosforamida para o meio extracelular, ela pode funcionar como um transportador da fosforamida para o interior celular. A concentração sistêmica da 4-OH-CCF pode refletir, portanto, o estágio de ativação intracelular da $\mathrm{CCF}^{(49)}$.

A aldofosfamida e a 4-OH-CCF são irreversivelmente desativadas por uma reação oxidativa a 4-cetociclofosfamida e carboxifosfamida, respectivamente. Ambos compostos não possuem atividade alquilante e 
não estão envolvidos em toxicidade. A formação da carboxifosfamida a partir da aldofosfamida é a via metabólica de intoxicação mais importante da CCF. As enzimas aldeído desidrogenase (ALDH), particularmente a ALDH1, estão envolvidas na formação da carboxifosfamida a partir da aldofosfamida. A reação de desintoxicação catalisada pela ALDH compete com a reação de ativação que converte a aldofosfamida em fosforamida mostarda. A inclusão de um inibidor da atividade de ALDH durante a exposição do fármaco pode, portanto, aumentar a sensibilidade das células à ação citotóxica da CCF. Além do mais, tumores resistentes aos efeitos citotóxicos da CCF, frequentemente apresentam uma superexpressão de ALDH1 ou ALDH3A1. A atividade da ALDH1 é diminuída como consequência da administração da CCF, resultando numa conversão reduzida de aldofosfamida em carboxifosfamida. Isso ocorre principalmente devido à desativação da ALDH1 pela acroleína. A desintoxicação da 4-OH-CCF, fosforamida mostarda e acroleína também podem ocorrer via conjugação intracelular com a glutationa (GSH), ocorrendo espontaneamente ou mediada pela enzima glutationa-Stransferase (GST). Esse processo, em parte, depende da concentração intracelular da GSH e da atividade da $\mathrm{GST}^{(49)}$.

Durante a terapia com CCF, foi constatada diminuição de antioxidantes no plasma e tecidos ${ }^{(48)}$. Têm sido demonstrado que a CCF pode ser nefrotóxica, tanto em modelos humanos quanto em animais. Seu uso pode resultar em disfunção glomerular e tubular ${ }^{(54)}$. Os idosos e as crianças (devido ao efeito tóxico no desenvolvimento do rim) são os mais suscetíveis à nefrotoxicidade pela CCF. A nefrotoxicidade da CCF está relacionada à dose e inclui redução variável do RFG, juntamente com disfunção tubular. Em criança recebendo quimioterapia, foram relatadas proteinúria glomerular e tubular e redução do $\mathrm{RFG}^{(55)}$.

A hipótese deste estudo é que, pelas ações antioxidante e antiinflamatória, o Ema possa ter efeito renoprotetor na LRA nefrotóxica induzida pela CCF. Estudos experimentais que buscam elucidar mecanismos intrínsecos de síndromes sistêmicas se justificam pela 
possibilidade de identificação de agentes inovadores no controle de doenças crônicas e agudas, e que contribuiriam significativamente para redução da alta mortalidade e de custos para o tratamento de pacientes em situações graves.

Para utilização do Ema como fitomedicamento, é necessário o desenvolvimento de novos estudos que comprovem seus efeitos benéficos e destaquem sua toxicidade. Pesquisas que visem propor parâmetros para a execução do controle de qualidade e segurança dos fitomedicamentos trarão contribuições neste sentido.

Considerando a utilização da CCF como quimioterápico em diversas neoplasias e seu efeito nefrotóxico, este estudo visa verificar 0 efeito protetor do Ema na nefrotoxicidade induzida pela CCF em experimentos com ratos. 
2OBJETIVOS 


\section{OBJETIVOS}

\subsection{GERAL}

$\checkmark$ avaliar o efeito do Echinodorus macrophyllus sobre a função renal de ratos

\subsection{ESPECÍFICOS}

$\checkmark$ avaliar a função renal (FR) de ratos submetidos ao tratamento com ciclofosfamida;

$\checkmark$ avaliar o efeito do Echinodorus macrophyllus sobre a função renal de ratos submetidos ao tratamento com ciclofosfamida;

$\checkmark$ avaliar o perfil oxidativo renal dos animais tratados com ciclofosfamida e Echinodorus macrophyllus;

$\checkmark$ realizar análise histopatológica dos rins dos animais tratados com ciclofosfamida e Echinodorus macrophyllus. 
3 MATERIAL EMÉTODOS 


\section{MATERIAL E MÉTODOS}

\subsection{MATERIAIS}

\subsubsection{Animais}

Todos os procedimentos realizados neste estudo estão de acordo com os Princípios Éticos de Experimentação Animal adotado pela Sociedade Brasileira de Ciência de Animais de Laboratórios - SBCAL e foram aprovados pela Comissão de Ética no Uso de Animais - CEUA - do Instituto de Ciências Biomédicas-IV da Universidade de São Paulo (Anexo A).

Foram utilizados ratos da raça Wistar, machos, adultos, pesando entre 250-310g. Os animais foram mantidos com livre acesso a água e alimentos e permaneceram em condições térmicas com ciclos alternados de dia e noite.

\subsection{PROCEDIMENTOS}

\subsubsection{Administração da ciclofosfamida}

A CCF (Genuxal ${ }^{\circledR}$ - Baxter, Brasil) foi diluída em solução fisiológica de cloreto de sódio $(\mathrm{NaCl}$ 0,9\%) e os animais receberam o tratamento com $150 \mathrm{mg} / \mathrm{kg}$ por via intraperitoneal (i.p.) em dose única, para indução da nefrotoxicidade. 


\subsubsection{Administração do Echinodorus macrophyllus}

O extrato bruto da folha do Echinodorus macrophyllus (Santo chá produtos naturais Ltda.) foi diluído em água filtrada fervente, permanecendo por 20 minutos. Após resfriamento, os animais receberam o pré-tratamento com $2 \mathrm{~g} / \mathrm{kg}$, via oral (v.o.) por gavagem, por 5 dias para renoproteção.

\subsubsection{Apresentação dos grupos experimentais}

Controle: animais que receberam solução de $\mathrm{NaCl} 0,9 \%$ por via i.p. $(1,5 \mathrm{ml} / \mathrm{kg}$, dose única).

Ema: animais que receberam Echinodorus macrophyllus, por gavagem (2g/kg, 1 x ao dia, durante 5 dias).

CCF: animais que receberam ciclofosfamida, por via i.p. (150mg/kg, dose única).

CCF + Ema: animais que receberam Echinodorus macrophyllus, por gavagem $\left(2 \mathrm{~g} / \mathrm{kg}\right.$, durante 5 dias) e ciclofosfamida no $5^{\circ}$ dia por via i.p. (150mg/kg, dose única).

No $6^{\circ}$ dia do experimento, os animais foram colocados na gaiola metabólica para coleta de urina de 24 horas e no $7^{\circ}$ dia foram eutanasiados para obtenção da amostra sanguínea e posterior avaliação da função renal e de metabólicos oxidativos. 


\subsubsection{Protocolo Experimental}

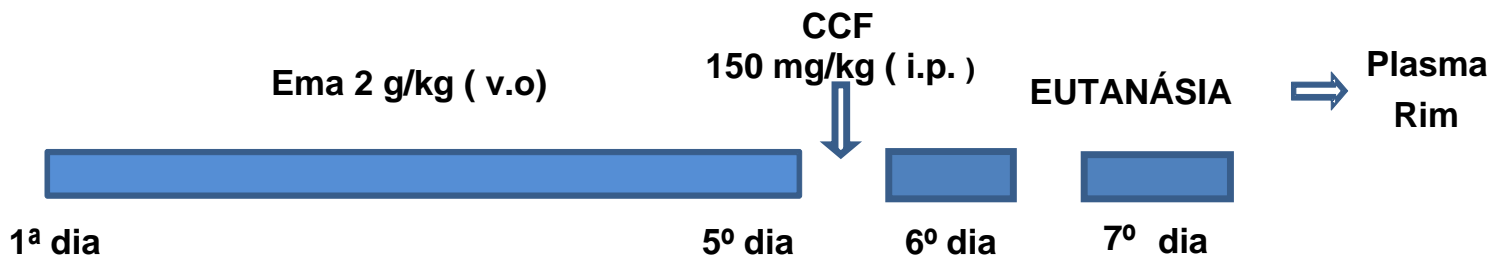

GAIOLA METABÓLICA

$\sqrt{1}$

Urina

Figura 2 - Protocolo Experimental

\subsubsection{Gaiola Metabólica}

Ao final do protocolo, os animais dos diversos grupos foram colocados em gaiolas metabólicas para mensuração do volume urinário, ingestão hídrica, ingesta alimentar e foi realizada coleta de amostra urinária de 24 horas para realização de estudos de função renal e estresse oxidativo. (Figura 3).
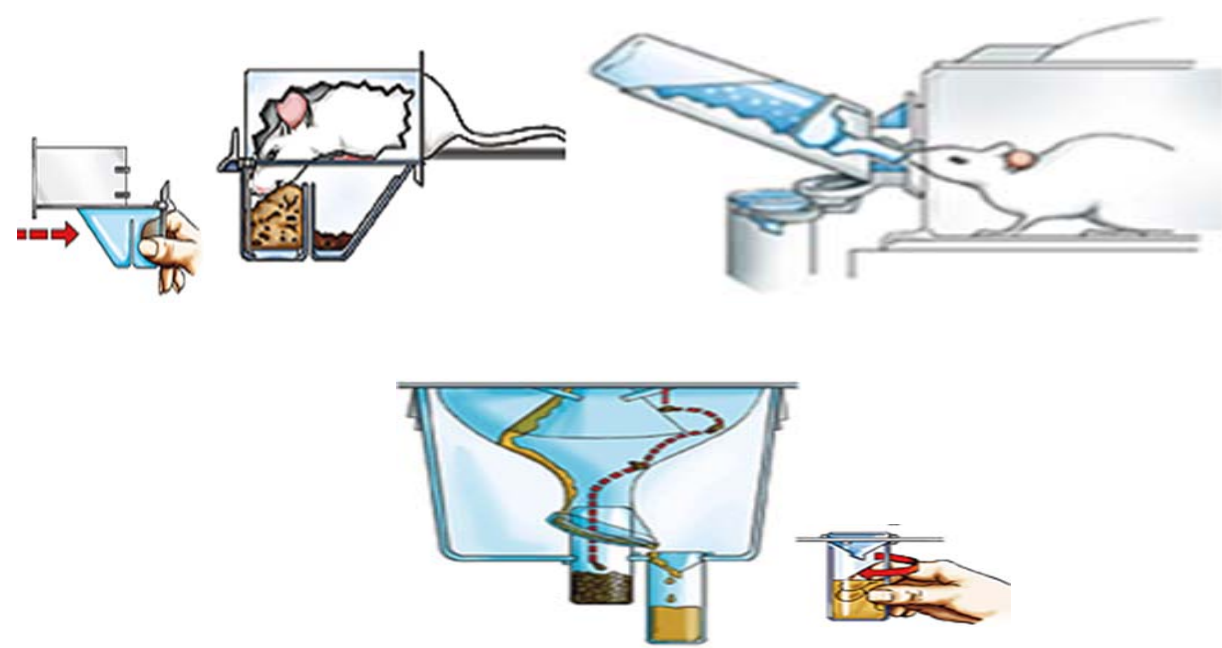

Figura 3 - Gaiolas metabólicas 


\subsubsection{Coleta de amostras e preparo do tecido renal}

Após a retirada das gaiolas metabólicas, os animais foram anestesiados com Thiopentax ${ }^{\circledR}$ (Cristália, Brasil) (tiopental sódico 40$60 \mathrm{mg} / \mathrm{kg}$, i.p.) e submetidos à laparotomia para coleta de sangue, por meio da punção da aorta abdominal, para estudos de função renal.

O rim esquerdo foi retirado, imerso em solução de metacarne e resfriado a $-4^{\circ} \mathrm{C}$ por 24 horas. Após esse período, o tecido renal foi acondicionado em álcool $70 \%$, desidratado e embebido em parafina para cortes histológicos. A coloração do tecido renal foi realizada com hematoxilina-eosina e montagem final das lâminas para posterior análise histológica. O rim direito foi imediatamente resfriado e acondicionado a $-80^{\circ} \mathrm{C}$ para estudos posteriores de mensuração das enzimas antioxidantes.

Ao final do experimento, foi realizada a eutanásia do animal, segundo as normas éticas para manuseios de animais em laboratório de pesquisa.

\subsection{MÉTODOS}

\subsubsection{Função renal}

\subsubsection{Clearance de creatinina}

A filtração glomerular (FG) foi avaliada por meio da metodologia do clearance de creatinina a partir da dosagem das creatininas sérica e urinária. A dosagem de creatinina urinária e plasmática foi determinada por colorimetria pelo método de Jaffé(56). 
O Clearance de creatinina (Clcr) foi calculado através da fórmula (1):

Clearance de Creatinina $=\frac{\text { Creatinina urinária } \times \text { fluxo urinário }}{\text { Creatinina sérica }}$

Os valores do clearance de creatinina por 100 gramas foram expressos por $\mathrm{ml} / \mathrm{min}$.

\subsubsection{Dosagem de creatinina plasmática}

A desproteinização do plasma consiste na primeira fase para a dosagem da creatinina plasmática. Para tal, $0,5 \mathrm{ml}$ de plasma foram diluídos em 1,5ml de água destilada (1:5) que então recebeu 0,25 $\mathrm{ml}$ de tungstato de sódio $10 \%\left(\mathrm{Na}_{2} \mathrm{O}_{4} \mathrm{~W}\right)$ e $0,25 \mathrm{ml}$ de ácido sulfúrico $\left(\mathrm{H}_{2} \mathrm{SO}_{4}\right)$ $0,75 \mathrm{~N}$. Após homogeneização, a solução foi centrifugada durante 10 minutos a $5.000 \mathrm{rpm}$ e $1,5 \mathrm{ml}$ do sobrenadante foi reservado para próxima fase.

Foram adicionados ao sobrenadante $0,3 \mathrm{ml}$ de hidróxido de sódio $(\mathrm{NaOH}) 0,75 \mathrm{~N}$ e $0,3 \mathrm{ml}$ de ácido pícrico $\left(\mathrm{C}_{6} \mathrm{H}_{3} \mathrm{~N}_{3} \mathrm{O}_{7}\right)$ 0,036M. A solução foi homogeneizada e permaneceu em repouso por 20 minutos em temperatura ambiente. A leitura foi realizada em espectrofotometria em absorbância em $520 \mathrm{~nm}$. Os resultados foram expressos em mg/dl.

\subsubsection{Dosagem de creatinina urinária}

Para a dosagem de creatinina urinária, foi preparada a seguinte solução: $0,05 \mathrm{ml}$ de urina diluída em $5 \mathrm{ml}$ de água destilada (1:1000), $1 \mathrm{ml}$ $\mathrm{NaOH}$ a $0,75 \mathrm{~N}$ e $1 \mathrm{ml}$ de $\mathrm{C}_{6} \mathrm{H}_{3} \mathrm{~N}_{3} \mathrm{O}_{7}$ a $0,036 \mathrm{M}$. Os mesmos 
procedimentos descritos anteriormente para mensuração de creatinina plasmática foram utilizados para mensuração da creatinina urinária.

O Clcr foi calculado através da seguinte fórmula:

Clcr = Creatinina urinária $(\mathrm{mg} / \mathrm{dl})$. Fluxo urinário $(\mathrm{ml} / \mathrm{min})$ de 24 horas

Creatinina plasmática

Os valores do Clcr foram expressos em $\mathrm{ml} / \mathrm{min}$

\subsubsection{Metabólitos oxidativos}

\subsubsection{Método FOX-2 para peróxidos urinários}

O método xilenol laranja versão-2 (FOX-2) consiste na determinação dos níveis de peróxidos através do método ferro-xilenol laranja ${ }^{(57,58)}$.

Os peróxidos oxidam íon $\mathrm{Fe}^{2+}$ para íon $\mathrm{Fe}^{3+}$ quando diluídos em solução ácida. O xilenol laranja [ácido (o-cresolsulfonaftalina 3' , 3" - bis (metilamino) ácido diacético] apresenta alta seletividade para o íon $\mathrm{Fe}^{3+}$ produzindo um complexo de coloração azul-arroxeado como demonstrado na equação (1): :(58) $^{(1)}$

$$
\mathrm{Fe}^{2+}+\mathrm{ROOH} \quad \mathrm{Fe}^{3+}+\mathrm{OH}^{-}(1)
$$

A solução FOX-2 segue a seguinte sequência:

$90 \mathrm{ml}$ de metanol e $10 \mathrm{ml}$ de água destilada;

$100 \mu \mathrm{M}$ xilenol laranja;

4 mM BHT (2[6]- di-tert-butil-p-cresol);

$25 \mathrm{mM}$ da solução de $\mathrm{H}_{2} \mathrm{SO}_{4}$

$250 \mu \mathrm{M}$ de sulfato ferroso de amônio - (Vetec Química, Brasil). 
A resultante da somatória dos reagentes acima consistiu na solução denominada FOX. Na etapa seguinte, $100 \mu$ la amostra urinária foi acrescentada em $900 \mu \mathrm{l}$ da solução FOX-2. Após homogeneização a solução permaneceu em repouso em temperatura ambiente durante 30 minutos. A leitura foi realizada por espectrofotometria em absorbância de $560 \mathrm{~nm}\left(\alpha=4,3 \times 10^{4} \mathrm{M}^{-1} \mathrm{~cm}^{-1}\right)$, após a retirada de resíduos de proteínas ou outros materiais por meio da centrifugação ${ }^{(59,60)}$.

Os valores foram estabilizados em nmol de peróxidos urinários por grama de creatinina urinária ${ }^{(59)}$.

\subsubsection{Dosagem de TBARS (substâncias reativas ao ácido tiobarbitúrico) na urina}

O Malondealdeído (MDA) é frequentemente analisado para a determinação dos índices de peroxidação lipídica por ser um dos principais produtos desta cascata. Um método para detecção deste produto é através da utilização do ácido tiobarbitúrico ao qual ele reage $^{(61)}$.

Na primeira etapa, $0,2 \mathrm{ml}$ da amostra de urina foi diluída em $0,8 \mathrm{ml}$ de água destilada. A essa solução foram adicionados $1,0 \mathrm{ml}$ de ácido tricloroacético (TCA) 17,5\% e 1,0 ml de ácido tiobarbitúrico 0,6\% (pH 2). A solução foi homogeneizada e colocada em água fervente (banho-maria) durante 20 minutos para reação com o ácido tiobarbitúrico.

$\mathrm{Na}$ etapa seguinte, a solução foi retirada do banho-maria e resfriada em gelo para adição de $1,0 \mathrm{ml}$ de TCA a $70 \%$. As amostras foram homogeneizadas e permaneceu em repouso durante 20 minutos em tubo de ensaio ocluído. Após esse período, a solução foi centrifugada durante 15 minutos a $3.000 \mathrm{rpm}$ e a leitura foi realizada em espectrofotometria em absorbância de 534nm $\left(\alpha=1,56 \times 10^{5} \mathrm{M}^{-1} \mathrm{~cm}^{-1}\right)^{(61)}$. 
Os valores foram expressos em nmol de TBARS por grama de creatinina urinária.

\subsubsection{Análise de tióis solúveis não protéicos no tecido renal}

A quantificação dos tióis seguiu com a homogeneização do tecido renal dos animais dos diferentes grupos com $2 \mathrm{ml}$ de solução $10 \mathrm{nM}$ de acetato de sódio ( $\mathrm{CH} 3 \mathrm{COONa})$ 0,5\%, tween-20 $\left(\mathrm{C}_{58} \mathrm{H}_{114} \mathrm{O}_{26}\right)$ e $100 \mu \mathrm{M}$ DTPA (dietilenotriamina-N,N,N',N'-penta-acetato) em pH 6,5. O homogenato foi centrifugado a $5.000 \mathrm{rpm}$ por 10 minutos a $4^{\circ} \mathrm{C}$ para retirada de debris teciduais. Uma alíquota foi reservada para imediata mensuração de proteínas totais. A segunda alíquota foi precipitada com TCA a 10\% (1:1) e novamente centrifugada a $5.000 \mathrm{rpm}$ por 10 minutos a $4^{\circ} \mathrm{C}$. O sobrenadante foi utilizado para a mensuração de tióis totais.

O volume de $400 \mu \mathrm{l}$ das amostras precipitadas e diluídas foram homogeneizadas em $200 \mu \mathrm{l}$ da solução com $1 \mathrm{mM}$ de DTNB (5,5'-ditio-bis (2-ácido nitrobenzoico) e $100 \mathrm{mM}$ de tampão Tris em pH 8,0. Após 10 minutos em temperatura ambiente, a quantidade de tióis foi determinada pela média da absorbância demonstrada em 412nm $\left(\alpha=13,6 \times 10^{3} \mathrm{M}^{-1} \mathrm{~cm}^{-}\right.$ $\left.{ }^{1}\right)$. A leitura foi realizada em espectrofotômetro ${ }^{(62)}$.

O equacionamento da mensuração de tióis solúveis foi ajustado para a contagem de proteínas total presentes no tecido renal, que exigiu a mensuração de proteínas por meio do uso do kit (BioRad, EUA) baseado no método Brad-ford, utilizando a albumina sérica bovina como padrão ${ }^{(73)}$.

Todos os valores obtidos foram estabilizados por nmol por mg de proteínas totais ${ }^{(63)}$. 


\subsection{ANÁLISE HISTOLÓGICA DO TECIDO RENAL}

\subsection{1 Área de lesão túbulointersticial: escala Shih}

A quantificação das alterações tubulointersticiais foi realizada por meio da escala de Shih. As alterações tubulointersticiais foram definidas como presença de necrose tubular, infiltrado inflamatório, dilatação tubular e atrofia tubular. As quantificações da lesão tubulointersticial foram graduadas na escala de 0 a 4 , onde $0=$ normal; $0,5=$ pequenas áreas focais; $\mathbf{1}$ = envolvimento de menos de $10 \%$ do córtex renal; $2=$ envolvimento de menos de $10-25 \%$ do córtex renal; 3 = envolvimento de $25-75 \%$ do córtex renal e 4 = envolvimento de mais de $75 \%$ do córtex renal $^{(64,65)}$.

\subsection{LOCAL}

Os experimentos descritos acima foram desenvolvidos no Laboratório Experimental de Modelos Animais (LEMA) da Escola de Enfermagem da Universidade de São Paulo - EEUSP, coordenado pela Prof $^{\mathrm{a}}$ Dr $^{\mathrm{a}}$ Maria de Fátima Fernandes Vattimo.

\subsection{RECURSOS FINANCEIROS}

Este estudo recebeu auxílio financeiro da Fundação de Amparo à Pesquisa do Estado de São Paulo (Fapesp) e da Pró-reitoria de Pesquisa da Universidade de São Paulo. 


\subsection{ANÁLISE ESTATÍSTICA}

A análise dos dados foi realizada através do método ANOVA para análise de variância e o nível de significância considerado foi $p<0,05$, considerando que o efeito de pelo menos um dos grupos fosse diferente dos outros. Os testes múltiplos de comparação 2 a 2 de Tukey foram utilizados para comparação ou não entre si. 
4 RESULTADOS 


\section{RESULTADOS}

\subsection{FUNÇÃO RENAL}

\subsubsection{Clearance de creatinina}

Tabela 1 -Resultados do peso corporal e função renal dos grupos Salina, Echinodorus macrophyllus (Ema), Ciclofosfamida (CCF) e Ciclofosfamida + Echinodorus macrophyllus (CCF+Ema) - São Paulo - 2013.

\begin{tabular}{lcccccc}
\hline Grupos & $\mathbf{n}$ & $\begin{array}{c}\text { Peso } \\
\text { (gramas) }\end{array}$ & $\begin{array}{c}\text { FU } \\
\text { (ml/min) }\end{array}$ & $\begin{array}{c}\text { CrU } \\
\text { (mg/dl) }\end{array}$ & $\begin{array}{c}\text { CrS } \\
\text { (mg/dl) }\end{array}$ & $\begin{array}{c}\text { Clcr/100g } \\
\text { (ml/min) }\end{array}$ \\
\hline Salina & 5 & $280 \pm 28$ & $0,013 \pm 0,003$ & $72,5 \pm 16,7$ & $0,37 \pm 0,06$ & $0,81 \pm 0,05$ \\
Ema & 6 & $290 \pm 11$ & $0,011 \pm 0,002$ & $73,1 \pm 13,6$ & $0,37 \pm 0,08$ & $0,77 \pm 0,14$ \\
CCF & 11 & $286 \pm 14$ & $0,016 \pm 0,005$ & $16,3 \pm 6,7^{\text {ab }}$ & $0,42 \pm 0,10$ & $0,20 \pm 0,05^{\text {ab }}$ \\
CCF+Ema & 11 & $293 \pm 21$ & $0,011 \pm 0,004$ & $43,1 \pm 12,5^{\text {abc }}$ & $0,50 \pm 0,12$ & $0,31 \pm 0,10^{\text {abc }}$ \\
\hline
\end{tabular}

Sendo: FU - Fluxo urinário, CrU - creatinina urinária, CrS - creatinina sérica, Clcr clearance de creatinina.

a $<0,001$ vs salina,

${ }^{\mathrm{b}} \mathrm{p}<0,001 \mathrm{vs}$ Ema,

c $p<0,05$ vs CCF,

Os valores representam média \pm desvio padrão.

Conforme demonstrado na Tabela 1, os animais não apresentaram variações significantes de peso corporal e de fluxo urinário entre os grupos.

Os grupos Salina e Ema não apresentaram variabilidade quanto ao Clcr $(0,81 \pm 0,05$ vs $0,77 \pm 0,14)$. O tratamento com dose única de CCF resultou em redução significativa do Clcr, caracterizando modelo de LRA por nefrotoxicidade $(0,20 \pm 0,05$ vs $0,81 \pm 0,05$ e $0,77 \pm 0,14 ; p<0,001)$. Observou-se que os animais tratados com CCF e que receberam o précondicionamento com Ema apresentaram aumento significativo do Clcr, quando comparados com o grupo CCF $(0,20 \pm 0,05$ vs $0,31 \pm 0,10)$. 


\subsection{METABÓLITOS OXIDATIVOS}

\subsubsection{Peróxidos urinários}

Tabela 2 -Resultados de peróxidos urinários dos grupos Salina, Echinodorus macrophyllus (Ema), Ciclofosfamida (CCF) e Ciclofosfamida + Echinodorus macrophyllus (CCF+Ema) - São Paulo - 2013.

\begin{tabular}{lcc}
\hline Grupos & $\mathbf{n}$ & $\begin{array}{c}\text { Peróxidos urinários } \\
\text { (nmol/g de creatinina) }\end{array}$ \\
\hline Salina & 5 & $25,6 \pm 6,5$ \\
Ema & 6 & $27,0 \pm 7,3$ \\
CCF & 11 & $73,9 \pm 24,0^{\mathrm{ab}}$ \\
CCF+Ema & 11 & $47,7 \pm 20,2^{\mathrm{abc}}$ \\
\hline
\end{tabular}

${ }^{a} p<0,001 v s$ Salina

${ }^{b} p<0,001$ vs Ema, ${ }^{c} p<0,01$ vs CCF

Os valores representam média \pm desvio padrão.

$\mathrm{O} \mathrm{H}_{2} \mathrm{O}_{2}$ está presente em todos os fluídos corporais, especialmente na urina. A mensuração dos níveis de peróxidos é considerada como biomarcador da geração de $\mathrm{H}_{2} \mathrm{O}_{2}$ e preditor da extensão de estresse oxidativo em modelos experimentais in vivo(66).

Os valores de peróxidos urinários dos grupos Salina e Ema, apresentados na Tabela 2 foram considerados como referência de normalidade $(25,6 \pm 6,5$ e $27,0 \pm 7,3)$.

O grupo CCF apresentou elevação significante dos valores de peróxidos urinários quando comparados com os grupos Salina e Ema $(73,9 \pm 24,0$ vs 25,6 $6 \pm 6,5$ e $27,0 \pm 7,3 ; p<0,001)$.

O grupo CCF+Ema apresentou redução na excreção de peróxidos

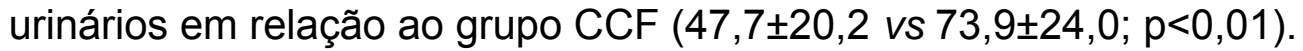




\subsubsection{Dosagem de TBARS (substâncias reativas ao ácido tiobarbitúrico) na urina}

Tabela 3 -Resultados da dosagem de substâncias reativas ao ácido tiobarbitúrico dos grupos Salina, Echinodorus macrophyllus (Ema), Ciclofosfamida (CCF) e Ciclofosfamida + Echinodorus macrophyllus (CCF+Ema) - São Paulo - 2013.

\begin{tabular}{lcc}
\hline Grupos & $\mathbf{n}$ & $\begin{array}{c}\text { TBARS urinário (nmol/g de } \\
\text { creatinina urinária) }\end{array}$ \\
\hline Salina & 5 & $0,3 \pm 0,1$ \\
Ema & 6 & $0,3 \pm 0,1$ \\
CCF & 11 & $4,6 \pm 1,9^{\mathrm{ab}}$ \\
CCF+Ema & 11 & $1,3 \pm 1,0^{\mathrm{abc}}$ \\
\hline
\end{tabular}

Sendo TBARS - substâncias reativas com ácido tiobarbitúrico

${ }^{a} p<0,001$ vs Salina

${ }^{a} p<0,001$ vs Ema

${ }^{c} p<0,001$ vs CCF

Os valores representam média \pm desvio padrão.

A tabela 3 apresenta os valores de TBARS urinários. Os resultados seguiram o padrão descrito para peróxidos urinários. Os grupos Salina e Ema foram considerados como referência de normalidade $(0,3 \pm 0,1)$.

O grupo CCF apresentou elevação significante de TBARS quando comparado com os grupos Salina e Ema $(4,6 \pm 1,9$ vs $0.3 \pm 0.1 ; p<0,001)$.

O grupo CCF+Ema apresentou redução estatisticamente significante de TBARS quando comparado com o grupo CCF $(1,3 \pm 1,0$ vs $4,6 \pm 1,9 ; p<0,001)$. 


\subsubsection{Tióis solúveis não proteicos no tecido renal}

Tabela 4 - Resultados de tióis no tecido renal dos grupos Echinodorus macrophyllus (Ema), Ciclofosfamidama (CCF) e Ciclofosfamida + Echinodorus macrophyllus (CCF+Ema), São Paulo - 2013

\begin{tabular}{lcc}
\hline Grupos & $\mathbf{n}$ & $\begin{array}{c}\text { Tióis no tecido renal } \\
\text { (nmol/mg de proteínas) }\end{array}$ \\
\hline Ema & 5 & $2,1 \pm 0,2$ \\
CCF & 8 & $1,2 \pm 0,4^{\mathrm{a}}$ \\
CCF+Ema & 11 & $2,4 \pm 0,4^{\mathrm{b}}$ \\
\hline
\end{tabular}

${ }^{a} p<0,001$ vs Ema

${ }_{\mathrm{p}}^{\mathrm{b}}<0,001$ vs CCF

Os valores representam média \pm desvio padrão.

Para tióis, foi adotado o grupo Ema como controle para os demais grupos, já que esse grupo tem demonstrado perfil idêntico ao Salina. Existem vários mecanismos antioxidantes de defesa determinados por enzimas, destacando-se a família da glutationa peroxidase. A GSH é um simples tripeptídeo com o grupamento tiol localizado na sua cadeia lateral, onde suas funções biológicas estão centradas. A GSH está presente em todas as células e se constitui como o principal tampão redox. O grupamento tiol passa por repetidos ciclos de redução $(\mathrm{GSH}-\mathrm{O}$ grupamento tiol encontra-se na forma de sulfidrila livre) e oxidação (GSSG - o grupamento tiólico de duas moléculas de GSH condensam através de uma ligação de dissulfeto) ${ }^{(67)}$.

A Tabela 4 demonstra o grupo Ema com maior concentração de tióis no tecido renal (Ema: 2,1 $\pm 0,2$ ), podendo ser usado como referência de normalidade nesse modelo. O grupo CCF apresentou redução dos níveis de tióis no tecido renal quando comparado com o grupo controle Ema (CCF: $1,2 \pm 0,4$ vs $2,1 \pm 0,23 ; p<0,001$ ). Foi observado que, no grupo CCF+Ema, o pré-condicionamento com Ema aumentou significativamente os níveis de tióis no tecido renal na comparação com o grupo CCF aproximando dos valores do grupo Ema (CCF+Ema: 2,4 $\pm 0,4$ e CCF: $1,2 \pm 0,4 ; p<0,001)$. 


\subsection{ANÁLISE HISTOLÓGICA DO TECIDO RENAL}

\subsection{1 Área de lesão túbulo intersticial: escala Shih}

Tabela 5 - Resultados das alterações tubulointersticial no tecido renal dos grupos Echinodorus macrophyllus (Ema), Ciclofosfamida (CCF) e Ciclofosfamida + Echinodorus macrophyllus (CCF+Ema), São Paulo - 2013

\begin{tabular}{lcc}
\hline Grupos & $\mathbf{n}$ & $\begin{array}{c}\text { Quantificação das alterações } \\
\text { tubulointersticial }\end{array}$ \\
\hline Ema & 5 & $0,04 \pm 0,04$ \\
CCF & 8 & $0,21 \pm 0,09^{\mathrm{a}}$ \\
CCF+Ema & 11 & $0,06 \pm 0,02^{\mathrm{b}}$ \\
\hline
\end{tabular}

${ }^{a} p<0,001$ vs Ema

$\mathrm{b}_{\mathrm{p}}<0,001$ vs CCF

Os valores representam média \pm desvio padrão.

A lesão tubulointersticial foi avaliada por meio da escala de Shih, na qual o grau de lesão foi graduado de 0 a 4 . A Tabela 5 apresenta o grau de lesão tubulointersticial dos diversos grupos segundo a escala de Shih.

O pré-tratamento dos animais com Ema $(\mathrm{A})$ demonstrou pequena alteração túbulointersticial, compatível com padrão de normalidade descrito em outros estudos, como do fitomedicamento Vitis vinifera $L$ na LRA induzida por tacrolimus ${ }^{(68)}$. O grupo CCF (B) mostrou elevação significativa desse marcador quando comparado ao grupo Ema $(0,21 \pm 0,09$ vs $0,04 \pm 0,04 ; p<0,001)$.

O grupo CCF+Ema demonstrou quantitativo de lesão tubulointersticial semelhante ao grupo Ema $(0,06 \pm 0,02 \quad 0,04 \pm 0,04)$ e significantemente menor do que o $\operatorname{CCF}(0,06 \pm 0,02$ vs $0,21 \pm 0,09, p<0,01)$

O efeito protetor da Ema (A) foi confirmado no grupo CCF+Ema (C), no qual observou-se redução significativa do grau de lesão 
tubulointersticial em relação ao grupo $\operatorname{CCF}(B)$ (CCF:0,21 $\pm 0,09$ vs $0,04 \pm 0,04 ; p<0,001)$.
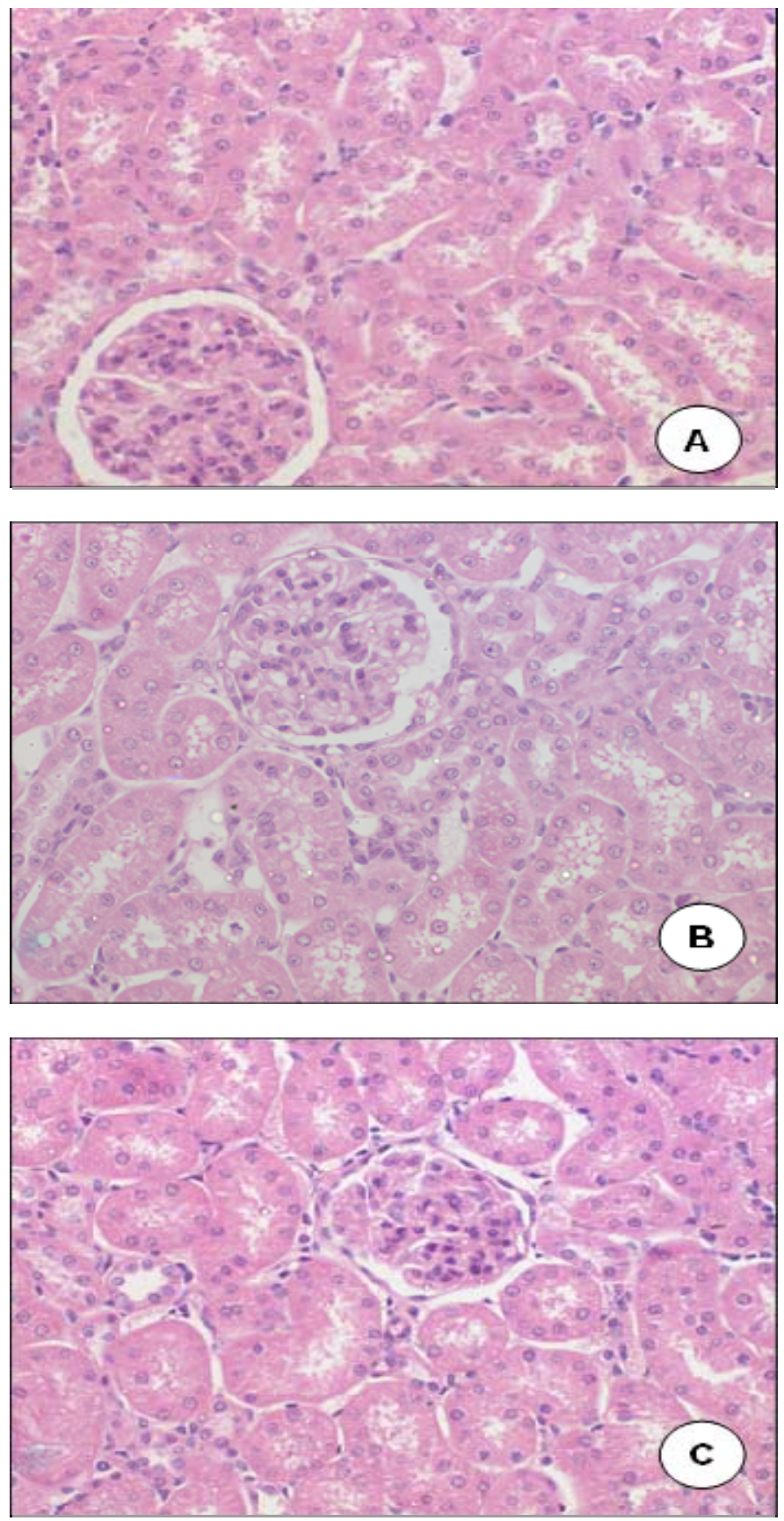

Figura 4 - Fotos de cortes histológicos para avaliação da área tubulointersticial (aumento 400x) dos grupos: Ema (A), CCF (B) e CCF+Ema (C). 


\section{DISCUSSÃO}




\section{DISCUSSÃO}

A LRA é uma síndrome que acomete $40 \%$ dos pacientes internados, principalmente na UTI, com uma mortalidade de $50 \%$. Tem como causas a hipoperfusão renal (eventos isquêmicos), sepse e uso indiscriminado de agentes terapêuticos nefrotóxicos ${ }^{(69)}$. Certas drogas são potencialmente nefrotóxicas, tais como os antibióticos, como os aminoglicosídeos, os antifúngicos, como a anfotericina $\mathrm{B}$; os quimioterápicos como a cisplatina; os radiocontrastes e imunossupressores como a ciclosporina. A nefrotoxicidade frequentemente está relacionada à dose ou à duração do tratamento. Além disso, a combinação com múltiplas drogas nefrotóxicas pode potencializar a toxicidade.

No tratamento de pacientes oncológicos, a nefrotoxicidade induzida por fármacos de uso comum e, muitas vezes mandatório, é um dos principais efeitos adversos. Esse estudo buscou avaliar o efeito da CCF sobre a função renal de ratos. A saber, a CCF é um quimioterápico alquilante utilizado no tratamento de tumores sólidos e não sólidos como as leucemias e linfomas, sendo ainda incorporado na clínica para a artrite e lúpus. Uma das maiores restrições para o uso da CCF é sua nefrotoxicidade.

O desenvolvimento de diferentes modelos animais de LRA, especialmente aqueles que simulam condições clínicas e seus tratamentos, tem contribuído para o entendimento da fisiopatologia da LRA, considerando a etiologia múltipla da lesão renal ${ }^{(70)}$. Assim, no sentido de elucidar os componentes determinantes da nefrotoxicidade da CCF, esse estudo realizou estudos de função, perfil oxidativo e análise histológica do tecido renal e introduziu o conceito de prevenção da lesão renal por meio do emprego de fitomedicamentos, com foco para o Ema. O Ema, também conhecido como chapéu de couro, possui grande volume de flavonoides em sua constituição, o que the atribui efeito antioxiodante, 
possivelmente renoprotetor. $O$ efeito de redução da nefrotoxicidade da CCF por meio do pré-condicionamento com o Ema foi a hipótese desse estudo.

Assim, a administração do quimioterápico CCF induziu LRA em ratos com liberação de EROs, que resultou no mecanismo de toxicidade tubular direta, característico da LRA tóxica por CCF. A caracterização da LRA teve como parâmetros a diminuição do Clcr, aumento de metabólitos oxidativos, diminuição dos níveis de tióis no tecido renal e a análise histológica do tecido renal dos animais desse grupo. Nesse contexto, observou-se que ação antioxidante do fitomedicamento Ema atenuou a redução da função renal. Resultado semelhante foi demonstrado em estudo realizado com o fitoterápico Uncaria tomentosa em modelo de LRA isquêmica ${ }^{(15)}$.

A diminuição do Clcr nesse estudo pode estar relacionada com a perda da manutenção ou da autorregulação da pressão intraglomerular, modulada pelas arteríolas aferentes e eferentes como forma de preservar o RFG e o débito urinário. Adicionalmente, os efeitos tóxicos da CCF incluem inflamação, microangiopatia trombótica e liberação de EROs.

A CCF compromete também as células tubulares proximais, que são vulneráveis aos efeitos tóxicos de medicamentos, uma vez que altera a função mitocondrial, interferindo no transporte tubular e gerando $E \mathrm{Es}^{(71)}$. A administração de CCF induz a liberação de EROs, como o radical $\mathrm{O}_{2}{ }^{\bullet-}$ e $\mathrm{OH}^{\bullet-}$ e de intermediários, como $\circ \mathrm{H}_{2} \mathrm{O}_{2}$, que resulta no consumo de enzimas antioxidantes. $O$ desequilíbrio entre cadeia de geração de EROs e enzimas antioxidantes desencadeia lesão celular oxidativa de origem nefrotóxica ${ }^{(39)}$.

Estudos realizados com diferentes medicamentos nefrotóxicos, como a gentamicina, radiocontrastes e outros quimioterápicos reforçam o significativo papel da lesão tubular no contexto das nefrotoxicidades $(72,73,74)$ 
Nesse estudo, os metabólitos oxidativos foram analisados por meio do método FOX-2 (peróxidos urinários), TBARS e tióis solúveis não proteicos no tecido renal. O grupo CCF apresentou elevação dos peróxidos e TBARS urinários e redução dos níveis de tióis no tecido renal, confirmando a participação do mecanismo oxidativo nesse modelo de LRA tóxica. Os ratos tratados com CCF+Ema demonstraram melhora da FR, vista pelo Clcr, e redução dos parâmetros oxidativos, o que reforça a ação renoprotetora e antioxidante do fitomedicamento. Resultado semelhante foi encontrado em estudo realizado para verificar o efeito protetor da Spirulina na LRA induzida pela $\mathrm{CCF}^{(48)}$. Ainda, ressaltando os efeitos relevantes quando da aplicação de fitomedicamentos em modelos de lesão que buscam elucidar questões da clínica, estudos demonstraram que o pré-condicionamento com Vittis vinifera, em animais submetidos à toxicidade pelo tacrolimus (FK), determinou efeito renoprotetor, com redução dos PUs e TBARS urinários e melhora do $\mathrm{Clcr}^{(68)}$.

Os achados com Ema podem ser atribuídos aos componentes ativos presentes no Ema. A cromatografia das folhas do Ema, realizada neste estudo, revelou a presença de flavonoides, componentes cujas propriedades antioxidantes já foram descritas. Dados semelhantes ressaltando os benefícios do pré-condicionamento com Ema foram descritos por estudo de modelo animal de nefrotoxicidade pela gentamicina $^{(75)}$.

Quanto à análise histológica, observou-se que os animais que receberam CCF demonstraram edema, desnudamento e vacuolização das células tubulares. Embora discretas, as lesões tubulointersticiais são semelhantes àquelas apresentadas em estudos sobre a toxicidade renal $^{(73,76)}$. Estudo com CCF demonstrou alterações histopatológicas em rins de ratos. O dano renal foi descrito como inflamação glomerular, vacuolização citoplasmática epitelial dos túbulos do córtex, edema intersticial, e alterações hemorrágicas leves no córtex renal. Contudo, quando foi instituído o pré-condicionamento com Ema, os animais que receberam CCF demonstraram significativa melhora das lesões 
histológicas, assemelhando-se ao grupo controle. Esse achado sugere que o fitomedicamento é capaz não só de interferir nos mecanismos funcionais, quanto na apresentação estrutural dessa nefrotoxicidade.

Estudos com fitomedicamentos têm evoluído nas últimas décadas, na tentativa de contribuir para o tratamento de doenças crônicas e agudas. Embora ainda haja necessidade de investigações sobre os efeitos adversos do Ema para sua introdução definitiva na prática clínica, os mecanismos antioxidantes protetores desse fitomedicamento o insere como possível alternativa de tratamento de prevenção da LRA nefrotóxica. 
6 CONCLUSÕES 


\section{CONCLUSÕES}

$\checkmark$ A ciclofosfamida induz lesão renal aguda nefrotóxica, confirmada pela redução do Clcr.

$\checkmark$ O Echinodorus macrophyllus apresenta efeito renoprotetor sobre a nefrotoxicidade da ciclofosfamida.

$\checkmark$ A ciclofosfamida eleva a excreção de peróxidos e MDA urinários e redução de tióis no tecido renal.

$\checkmark$ O Echinodorus macrophyllus possui ação antioxidante, reduzindo o estresse oxidativo induzido pela ciclofosfamida.

$\checkmark$ A ciclofosfamida induziu alterações na histologia renal, que foram atenuadas quando o Echinodorus macrophyllus foi administrado. 
REFERENCIAS 


\section{REFERÊNCIAS}

1. Brasil. Agência Nacional de Vigilância Sanitária. Consulta pública n.84, 22 de outubro de 2002. Dispõe sobre o registro de medicamentos fitoterápicos. Agência Nacional de Vigilância Sanitária, 2002[citado 2010 set. 27]. Disponível em: http://www4.anvisa.gov.br/tese/visadoc/CP/CP\%5B2920-1-5D.pdf

2. Brasil. Ministério da Saúde n.971, de 13 de maio de 2006. Institui a Política Nacional de Práticas Integrativas e Complementares no |Sistema Único de Saúde - PNPIC. Ministério da Saúd, 2006[citado 2010 set. 27]. Disponível em: http://portalsade/portal/pdf/PNPIC.pdf

3. Vidal LS, Alves AM, Kuster RM, Lage C, Leitão, AC. Genotoxicity and mutagenicity of Echinodorus macrophyllus (chapéu-de-couro) extracts. Genet Mol Biol. 2010; 33(3):549-57.

4. Arnous $\mathrm{AH}$, Santos AS, Beinner RPC. Plantas medicinais de uso caseiro - conhecimento popular e interesse por cultivo comunitário. Rev Espaço Saúde. 2005; 6(2):1-6.

5. Miguel MD, Miguel OG. Desenvolvimento de fitoterápicos. Ribeirão Preto: Tecmedd; 2004. p.18-9.

6. Silva MIG, Gondim APS, Nunes IFS, Sousa FCF. Utilização de fitoterápicos nas unidades básicas de atenção à saúde da família no município de Maracanaú (CE). Rev Bras Farmacogn. 2006; 16(4):45562.

7. Ribeiro AQ, Leite JPV, Dantas-Barros AM. Perfil de utilização de fitoterápicos em farmácias comunitárias de Belo Horizonte sob a influência da legislação nacional. Rev Bras Farmacogn. 2005; 15(1):6570.

8. Leite JPV, Pimenta DS, Gomes RSDL, Dantas-Barros AM. Contribuição ao estudo farmacobotânico da Echinodorus macrophyllus (Kunth) Micheli (chapéu-de-couro) - Alismataceae. Rev Bras Farmacogn. 2007; 17(2):242-48. 
9. Dornas WC, Oliveira TT, Rodrigues-das-Dores RG, Santos AF, Nagem TJ. Flavonóides: potencial terapêutico no estresse oxidativo. Rev Ciênc Farm Básica Apl. 2007; 28(3):241-49.

10. Da Costa Lopes L, Albano F, Augusto Travassos Laranja G, Marques Alves L, Fernando Martins e Silva L, Poubel de Souza G, et al. Toxicological evalution by in vitro and vivo assays of an aqueous extract prepared from Echinodorus macrophyllus leaves. Toxicol Lett. 2000; 116(3):189-98.

11. Ueki M, Ueno M, Morishita J, Maekawa N. Curcumin ameliorates cisplatin-induced nephrotoxicity by inhibiting renal inflammation in mice. $\mathrm{J}$ Biosci Bioeng. 2013; 115(5):547-51.

12. Chander V, Singh D, Chopra K. Reversal of experimental myoglobinuric acute renal failure in rats by quercetin, a bioflavonoid. Pharmacology. 2005; 73(1):49-56.

13. Hamsa TP, Kuttan G. Protective role Ipomoea obscura (L.) on cyclophosphamide-induced uro-and nephrotoxicities by modulating antioxidant status and pro-inflammatory cytokine levels. Inflammopharmacology. 2011; 19(3):155-67.

14. Bezerra JS, Teixeira W, Vattimo MFF. Efeito protetor da Vitis vinifera na lesão renal aguda isquêmica em ratos. J Bras Nefrol. 2008; 30(2):99104.

15. Vattimo MFF, Silva NO. Uncária tomentosa e a lesão renal aguda isquêmica em ratos. Rev Esc Enferm USP. 2011; 45(1):194-8.

16. Mehta RL, Kellum JÁ, Shah SV, Molitoris BA, Ronco C, Warnock DG, et al. Acute kidney Injury Network: report of an initiative to improve outcomes in acute kidney injury. Crit Care. 2007; 11(2):R31.

17. Cheung CM, Ponnusamy A, Anderton JG. Management of acute renal failure in the elderly patient: a clinician's guide. Drugs Aging. 2008; 25(6):455-76.

18. Bagshaw SM, Langenberg C, Wan L, May CN, Bellomo R. A systematic review of urinary findings in experimental septic acute renal failure. Crit Care Med. 2007; 35(6):1592-8. 
19. Venkataraman R, Kellum JA. Defining acute renal failure: the RIFLE criteria. J Intensive Care Med. 2007; 22(4):187-93.

20. Hoste EA, Shurgers M. Epidemiology of acute kidney injury: how big is the problem? Crit Care Med. 2008; 36(4 Suppl):S146-51.

21. Nunes TF, Brunetta DM, Leal CM, Pisi PCB, Roriz-Filho JS. Insuficiência renal aguda. Medicina (Ribeirão Preto). 2010; 43(3):272-82.

22. Pannu N, Nadim MK. An overview of drug-induced acute kidney injury. Crit Care Med. 2008; 36(4 Suppl):S216-23.

23. Uchino S, Kellum JA, Bellomo R, Doig GS, Morimatsu H, Morgera S, et al. Acute renal failure in critically ill patients: a multinational, multicenter study. JAMA. 2005; 294(7):813-8.

24. Perazella MA. Renal vulnerability to drug toxicity. Clin J Am Soc Nephrol. 2009; 4(7):1275-83.

25. Cummings BS, Schnellmann RG. Pathophysiology of nephrotixic cell injury. In: Schrier RW, editor. Diseases of the kidney and urogenital tract. Philadelphia: Lippincott Williams\&Wilkinson; 2001. p.1071-136.

26. Kaloyanides GJ, Bosmans JL, DeBroe ME. Antibiotic and immunosuppression-related renal failure. In: Schrier RW, editor. Diseases of the kidney and urogenital tract. Philadelphia: Lippincott Williams\&Wilkinson; 2001. p.1137-74.

27. Schetz M, Dasta J, Goldstein S, Golper T. Drug-induced acute kidney injury. Curr Opin Crit Care. 2005; 11(6):555- 65.

28. Lamieire $\mathrm{NH}$, Flombaum $\mathrm{CD}$, Moreau $\mathrm{D}$, Ronco $\mathrm{C}$. Acute renal failure in cancer patients. Ann Med. 2005; 37(1):13-25.

29. Sheridan AM, Bonventre JV. Cell biology and molecular mechanisms of injury in ischemic acute renal failure. Curr opin nephrol Hypertens. 2000; 9(4):427-34.

30. Devarajan P. Cellular and molecular derangements in acute tubular necrosis. Curr Opin Pediatr. 2005; 17(2):193-9.

31. Bellomo R, Ronco C, Kellum JA, Mehta RL, Palevsky P. Acute Dialysis Quality Onitiative workgroup. Acute renal failure - definition, outcome measures, animal models, fluid therapy and information technology 
needs: the Second International Consensus Conference of the Acute Dialysis Quality Initiative (ADQI) Group. Crit Care. 2004; 8(4):R204-12.

32. Monte JC, Manoel ALO. Análise dinâmica da lesão renal aguda: aplicação de um modelo matemático. Einstein. 2009; 7(4):465-8.

33. Dezoti C, Watanabe M, Pinto CF, Neiva LBM, Vattimo MFF. Proteção funcional da enzima heme-oxigenase-1 na lesão renal aguda isquêmica e tóxica. Acta Paul Enferm. 2009; 22(Especial-Nefrologia):490-3.

34. Nath KA, Norby SM. Reactive oxygen species and acute renal failure. Am J Med. 2000; 109(8):665-78.

35. Devarajan P. Update on mechanisms of ischemic acute kidney injury. J Am Soc Nephrol. 2006; 17(6):1503-20.

36. Molitoris BA. Acute renal failure: cellular basis of Ischemic acute renal failure. In: Brenner BM. The Kidney. $6^{\text {th }}$ ed. Philadelphia: WB Saunders Company; 2000. v.1, p.1-4.

37. Brady HR, Brenner BM, Clarkson MR, Lieberthal W. Acute renal failure: acute tubule necrosis. In: Brenner BM. The Kidney. $6^{\text {th }}$ ed. Philadelphia: WB Saunders Company; 2000. v.1. p.1201-32.

38. Okusa MD. The inflammatory cascade in acute ischemic renal failure. Nephron. 2002; 90(2):133-8.

39. Nordberg J, Arnér ES. Reactive oxygen species, antioxidant and the mammalian thiredoxin systems. Free Radic Biol Med. 2001; 31(11):1287312.

40. McCord JM. The evolution of free radical and oxidative stress. Am J Med. 2000; 108(8):652-9.

41. Sener G, Sener E, Sehirli O, Ogunç AV, Cetinel S, Gedik N, et al. Ginkgo biloba extract ameliorates ischemia reperfusion-induced renal injury in rats. Pharmacol Res. 2005; 52(3):216-22.

42. Luqmani YA. Mechanisms of drug Resistance in Cancer Chemotherapy. Med Princ Pract. 2005; 14(Suppl 1):35-48.

43. Luisi FA, Petrilli AS, Tanaka C, Caran EM. Contribution to the treatment of nausea and emesis induced by chemotherapy in children and adolescents with osteosarcoma. São Paulo Med J. 2006; 124(2):61-5. 
44. Perez RR, Silva MAML, Varzim FLSB, Oliveira SB, Hucke ETS. A ação do decanato de nadrolona (Deca-durabolin) sobre parâmetros hematológicos e proteína total plamática de ratos (Rattus rattus) com depressão medular induzida após a administração de sulfato de vincristina (Oncovin). Ciênc Rural. 2005; 35(3):589-95.

45. Almeida VL, Leitão A, Reina LDCB, Montanari CA, Donnici CL. Câncer e agentes antineoplásicos ciclo-celular não específicos que interagem com o DNA: uma introdução. Quim Nova. 2005; 28(1):118-29.

46. Ferdinandi DM, Ferreira AA. Agentes alquilantes: reações adversas e complicações hematológicas. AC\&T Científica. 2009; 1(1):1-12.

47. Sobral FRS. Proposta de guia para a realização de estudos não clínicos de segurança, necessários ao desenvolvimento de medicamentos antineoplásicos [dissertação]. Brasília: Universidade Federal da Bahia; 2006.

48. Sinanoglu O, Yener AN, Ekici S, Mid A, Aksungar FB. The Protective effects of spirulina in cyclophosphamide induced nephrotoxicity and urotoxicity in rats. Urology. 2012; 80(6):1392. e1-6.

49. De Jonge ME, Huitema AD, Rodenhuis, Beijnen JH. Clinical pharmacokinetics of cyclophosphamide. Clin Pharmacokinet. 2005; 44(11):1135-64.

50. Korkmaz A, Topal T, Oter S. Pathophysiological aspects of cyclophosphamide and ifosfamide induced hemorrhagic cystitis; implication of reactive oxygen and nitrogen species as well as PARP activation. Cell Biol Toxicol. 2007; 23(5):303-12.

51. Zhang J, Tian Q, Chan SY, Li SC, Zhou S. Metabolism and transport of oxazaphosphorines and the clinical implications. 2005;37(4):611-703.

52. Adams Jr D., Klaidman LK. Acrolein-induced oxygen radical formation. Free Radic Biol Med. 1993; 15(2):187-93.

53. Sugiyama A, Sun J, Nishinohara M, Fujita $Y$, Masuda A, Ochit $T$, Takeuchi T. Expressions of lipid oxidation markers, $N(\varepsilon)$-Hexanoyl lysine and acrolein in cisplatin-induced nephrotoxicity in rats. J Vet Med Sci. 2011; 73(6):821-6. 
54. Sugumar E, Kanakasabapathy I, Abraham P. Normal plasma creatinine level despite histological evidence of damage and increased oxidative stress in the kidneys of cyclophosphamide treated rats. Clin Chim Acta. 2007; 376(1-2):244-5.

55. Abraham P, Rabi S. Nitrosative stress, protein tyrosine nitration, PARP activation and NAD depletion in the kidneys of rats after single dose of cyclophosphamide. Clin Exp Nephrol. 2009; 13(4):281-7.

56. Dorea EL, YU L, De Castro I, Campos SB, Ori M, Vaccari EM, et al. Nephrotoxicity of amphotericin B is attenuated by solubilizing with lipid emulsion. J Am Soc Nephrol. 1997; 8(9):1415-22.

57. Gay C, Collins J, Gebicki JM. Hydrogen peroxide assay with the ferricxylenol orange complex. Anal Biochem. 1999; 273(2):149-55.

58. Wolff SP. Ferrous ion oxidation in presence of ferric in indicator xilenol orange for measurement of hydroperoxides. Methods Enzymol. 1994; 233:182-9.

59. Banerjee D, Madhusoodanan UK, Nayak S, Jacob J. Urinary Hydrogen peroxide: a probably marker of oxidative stress in malignancy. Clin Chim Acta. 2003; 334(1/2):205-9.

60. Lima ES, Abdalla DSP. Peroxidação lipídica: mecanismos e avaliação em amostras biológicas. Rev Bras Cienc Farm. 2001; 37(3):293-303.

61. Walker PD, Shah SV. Reactive oxygen metabolites in endotoxin-induced acute renal failure in rats. Kidney Int. 1990; 38(6):1125-32.

62. Akerboom TPM, Sies H. Assay glutathione, glutathione disulfide, and glutathione mixed disulfides in biological samples. Methods Enzymol. $1981 ; 77: 373-82$.

63. Read SM, Northcote DH. Minimization of the response to different protein of the coomassie blue $\mathrm{G}$ dye-binding assay for protein. Anal Biochem. $1981 ; 116(1): 53-64$.

64. Shin W, Hines WH, Neilson EG. Effects of cyclosporine: A development of immune-mediated intersticial nephitis. Kidney Int. 1988; 33(6):1113-8.

65. Francescato HDC, Costa RC, Silva CGA, Coimbra TM. Treatment p38 MAPK inhibitior attenuates cisplatin nephrotoxicity starting after beginning of renal demage. Life Sci. 2009; 84(17-18):590-7. 
66. Long LH, Evans PJ, Halliwell B. Hydrogen peroxide in human urine: implications for antioxidant defense and redox regulation. Biochem Biophys Res Commun. 1999; 262(3):605-9.

67. Filomeni G, Rotilio G, Ciriolo MR. Cell signally and the glutathione redox system. Biochem Pharmacol. 2002; 64:1057-64.

68. Silva WT, Santos JG, Watanabe M, Vattimo MFF. Efeito renoprotetor dos flavonoides do vinho na nefrotoxicidade do imunossupressor Tacrolimus. Acta paul. enferm. 2011;24(3):388-92.

69. Peres LAB, Duarte PAD, Venazzi A, Brito AA, Nascimento GH, Matsuo T. Preditores de lesão renal aguda e de mortalidade em unidade de terapia intensiva. Rev Soc Bras Clin Med. 2012; 10(2):106-11.

70. Sing AP, Junemann A, Muthuraman A, Jaggi AS, Singh N, Grover K et al. Animal models of acute renal failure. Pharmacol Res. 2012; 64(1):3144.

71. Naughton CA. Drug-Induced Nephrotoxicity. Am Fam Physician. 2008; 78(6):743-50.

72. Hosaka EM, Santos OFP, Seguro AC, Vattimo MFF. Effect of cyclooxygenase inhibitiors on gentamicin-induced nephrotoxicity in rats. Braz J of Med Biol Res. 2004; 37(7):979-85.

73. Pinto CF, Watanabe M, Vattimo MFF. Hydration and N-acetylcysteine in acute renal failure caused by iodinate medium: an experiment with rats. J Nephrol. 2008; 21(5):783-8.

74. Zhang J, Lu H. Ifosfamide induces acute renal failure via inhibition of the thioredoxin reductase activity. Free Radic Bio Med. 2007; 43(12):1574-83

75. Portella VG, Cosenza GP, Diniz LRL, Pacheco LF, Cassali GD, Caliari MV et al. Nephroprotective Effect of Echinodorus Macrophyllus Micheli on Gentamicin-Induced Nephrotoxicity in Rats. Nephron Extra. 2012; 2(1):177-83.

76. Fonseca CD, Watanabe M, Vattimo MFF. Role of heme oxygenase-1 in polymyxin B-induced Nephrotoxicity in rats. Antimicrob Agents Chemother. 2012; 56(10):5082-7. 
ANEXO 


\section{ANEXO}

\section{Anexo A - PARECER DO COMITÊ DE ÉTICA EM EXPERIMENTO ANIMAL}

\section{Certificado}

Certificamos que o protocolo registrado sob $n^{\circ} \mathbf{0 5 5}$ nas fls. $\mathbf{1 2 8}$ do livro $\mathbf{0 2}$ para uso de animais em experimentação, sob a responsabilidade do Prof(a) Dr(a)) Maria de Fátima Fernandes Vattimo, Coordenador (a) da Linha de pesquisa "Efeito protetor do Echinodorus macrophyllus na lesão renal aguda induzida pela Ciclofosfamida" do qual participam o(s) aluno(s) Espedito Ladier do Nascimento, está de acordo com os Princípios Éticos de Experimentação Animal adotado pela Sociedade Brasileira de Ciência de Animais de Laboratório (SBCAL) e foi aprovado pela COMISSÃO DE ÉTICA NO USO DE ANIMAIS (CEUA) em 26.06.2012, com validade de 4 anos.

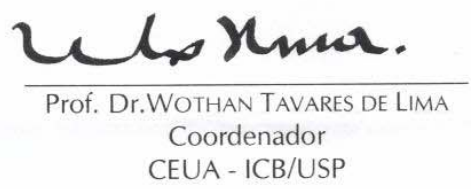

São Paulo, 27 de junho de 2012.

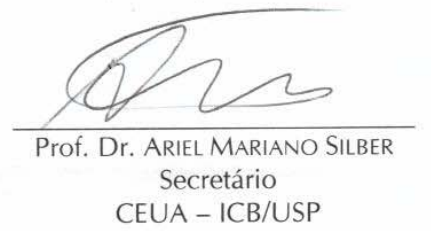

